\title{
Scoring systems in clinical small-bowel capsule endoscopy: all you need to know!
}

\section{(ㄷ)(1)}

Authors

Bruno Rosa ${ }^{1,2,3}$, Reuma Margalit-Yehuda ${ }^{4}$, Kelly Gatt ${ }^{5}$, Martina Sciberras ${ }^{5}$, Carlo Girelli ${ }^{6}$, Jean-Christophe Saurin ${ }^{7}$, Pablo Cortegoso Valdivia ${ }^{8}$, Jose Cotter ${ }^{1,2,3}$, Rami Eliakim ${ }^{4}$, Flavio Caprioli ${ }^{9}$, Gunnar Baatrup ${ }^{10}$, Martin Keuchel ${ }^{11}$, Pierre Ellul ${ }^{5}$, Ervin Toth ${ }^{12}$, Anastasios Koulaouzidis ${ }^{13,14}$

Institutions

1 Gastroenterology Department, Hospital da Senhora da Oliveira, Guimarães, Portugal

2 Life and Health Sciences Research Institute (ICVS), School of Medicine, University of Minho-Braga. Portugal

3 ICVS/3B's, PT Government Associate Laboratory Braga/Guimarães, Portugal.

4 Department of Gastroenterology, Sheba Medical Center, Sackler School of Medicine, Tel-Aviv, Israel

5 Division of Gastroenterology, Mater Dei Hospital, Msida, Malta

6 Department of Internal Medicine, Gastroenterology \& Digestive Endoscopy, Hospital of Busto Arsizio, Italy

7 Hospices Civils de Lyon, Hôpital Edouard Herriot, Service d'Hépato-Gastro-Entérologie et d'Endoscopie Digestive, Lyon, France

8 Gastroenterology \& Endoscopy Unit, University Hospital of Parma, University of Parma, Parma, Italy

9 Unit of Gastroenterology and Endoscopy, Fondazione IRCCS Cà Granda, Ospedale Policlinico di Milano, Milan, Italy

10 Department of Clinical Research, University of Southern Denmark, Odense, Denmark

11 Clinic for Internal Medicine, Bethesda Krankenhaus Bergedorf, Hamburg, Germany

12 Skåne University Hospital, Lund University, Malmö, Sweden

13 Endoscopy Unit, The Royal Infirmary of Edinburgh, Scotland, UK

14 Department of Social Medicine \& Public Health, Pomeranian Medical University, Szczecin, Poland

submitted 1.9.2020

accepted after revision 26.11.2020

Bibliography

Endosc Int Open 2021; 09: E802-E823

DOI 10.1055/a-1372-4051

ISSN 2364-3722

(c) 2021. The Author(s).
This is an open access article published by Thieme under the terms of the Creative Commons Attribution-NonDerivative-NonCommercial License, permitting copying and reproduction so long as the original work is given appropriate credit. Contents may not be used for commercial purposes, or adapted, remixed, transformed or built upon. (https://creativecommons.org/licenses/by-nc-nd/4.0/) Georg Thieme Verlag KG, Rüdigerstraße 14,

70469 Stuttgart, Germany

Corresponding author

Anastasios Koulaouzidis MD, DM, PhD Affiliated Professor, Department of Social Medicine \& Public Health, Pomeranian Medical University, 70-204 Szczecin, ul. Rybacka 1, Poland Fax: +447565 440303

akoulaouzidis@hotmail.com

\section{ABSTRACT}

Capsule endoscopy (CE) emerged out of the pressing clinical need to image the small bowel (SB) in cases of midgut bleeding and provide an overall comfortable and reliable gastrointestinal (GI) diagnosis [1]. Since its wider adoption in clinical practice, significant progress has been made in several areas including software development, hardware features and clinical indications, while innovative applications of CE never cease to appear [2,3]. Currently, several manufacturers provide endoscopic capsules with more or less similar technological features [4]. Although there is engaging and continuous academic and industry-fueled R\&D, promising furtherment of CE technology [4, 5], the current status of clinical CE remains that of by and large an imaging modality. Clinical relevance of CE images is cornerstone in the decision-making process for medical management. In one of the larger to date SB CE studies, 4,206 abnormal images were detected in 3,280 patients [6]. Thus, CE leads to the identification of a large amount of potential pathology, some of which are pertinent (or relevant) while some (probably the majority) are not.

Soon artificial intelligence $(\mathrm{Al})$ is likely to carry out several roles currently performed by humans; in fact, we are witnessing only the first stages of a transition in the clinical adoption of Al-based solutions in several aspects of gastroenterology including CE [7]. Until then though, human- 
based decision-making profoundly impacts patient care and - although not suggested in the updated European Society of Gastrointestinal Endoscopy (ESGE) European curriculum $[8,9]$ - it should be an integral part of CE training. Frequently, interpretation of CE images by experts or at least experienced readers differs. In a tandem CE reading study, expert review of discordant cases revealed a $50 \%$ (13/25 discordant results) error rate by experienced readers, corresponding (in 5/13 cases) to 'over-classification' of an irrelevant abnormality [10]. Another comparative study showed an 'over-classification' of such irrelevant abnormalities in $\sim 10 \%$ of CE readings [11]. One thing which has been for a while on the table - in relation to optimizing and/or standardizing CE reporting and subsequent decision-making - is the need for reproducible scoring systems and for a reliable common language among clinicians responsible for further patient's management.

Over the years, several of these scoring systems were developed while others appear in the wake of software and hard- ware improvements aiming to replace and/or complement their predecessors. This review presents a comprehensive account of the currently available classification/scoring systems in clinical CE spanning from predicting the bleeding potential of identified SB lesions (with emphasis on vascular lesions), and the individual rebleeding risk; scoring systems for the prediction of SB lesions in patients with obscure gastrointestinal bleeding (OGIB), having the potential to improve patient selection and rationalize the use of enteroscopy, with better allocation of resources, optimized diagnostic workflow and tailored treatment. This review also includes scores for reporting the inflammatory burden, the cleansing level that underscores confidence in CE reporting and the mass or bulge question in CE. Essentially, the aim is to become a main text for reference when scoring is required and facilitate the inclusion of -through readiness of access- one of the other in the final report.

\section{Nomenclature \& classification of SB lesions with bleeding potential}

The diagnosis and interpretation of SB vascular lesions is not always straightforward. Therefore, the use of a common terminology and standardized classification system to describe the probability of haemorrhagic lesions in the SB is essential to improve our knowledge of the natural history, expected outcomes and optimize management of patients with midgut bleeding (MGB). A consensus statement on the nomenclature and semantic description of vascular lesions in small-bowel capsule endoscopy (SBCE) was recently established [12], aiming to improve standardization of reading, teaching, and medical research on this topic, Table 1. A similar methodology has been followed to standardize terminology of ulcerative and inflammatory lesions in CD [13], > Table 2.

MGB refers to SB bleeding originating distal to the ampulla of Vater and proximal to the ileocecal valve (ICV) [14]. It accounts for most cases of obscure GI bleeding (OGIB), representing $5 \%$ to $10 \%$ of all cases of Gl bleeding, and it presents clinically as occult (positive fecal occult blood tests and/or iron deficiency anemia [IDA]) or overt (melena or hematochezia) bleeding $[14,15]$. In a large systematic review of 227 SBCE studies, the CE detection rate of a causative factor in OGIB was $58.6 \%$, with $>50 \%$ of patients having angiectasias, followed by inflammatory lesions (26.8\%) and tumors (8.8\%) [16]. Admittedly, angiectasias are the most common source of OGIB in patients older than 60 years, while patients $<40$ years are more likely to have CD, Meckel's diverticula, and SB tumors $[17,18]$.

CE detects a lot of abnormal and/or unusual images in the SB; its limitation, therefore, is not sensitivity but specificity, and recognizing the relevance of any 'abnormal' images in the causation of MGB episodes. Based on our experience in therapeutic enteroscopy, the main risk for patients is - in fact - un- necessary enteroscopy prompted by overinterpretation of CE findings. Our practice is to reject at least one in three therapeutic enteroscopy requests after reviewing CE findings (unpublished data). In regard to the risk of rebleeding, predictive scoring systems have been validated and can be used for the stratification of individuals as low, intermediate or high risk. These practical models may be used to guide the decisions on the therapeutic approach and follow-up, aiming to improve the clinical outcomes of patients with MGB.

\section{Saurin classification/score}

In 2003, a simple classification for the clinical relevance of lesions detected in CE was proposed [19]. It has since become a widely known as Saurin score. With this classification, lesions detected on SB CE are graded as P0, P1, and P2, according to the potential of clinically significant bleeding ( $>$ Table 3 ). Saurin score has been validated by i) identical grading of highly relevant (P2) lesions by CE readers in a blind tandem study in $100 \%$ of cases, as compared to $73 \%$ and $27 \%$, respectively for P1 and P0 lesions; ii) high therapeutic impact $61 \%$ for P2 lesions versus $23 \%$ for $\mathrm{P} 1$ or P0 lesions; and iii) patient clinical followup [20]. More recently, a P3 category was included to indicate actively bleeding lesions [21]. The recent ESGE position on CE recommends Saurin score as a useful tool in the setting of OGIB [22], but can be easily adapted, in other clinical scenarios such as CE for example in Lynch syndrome, where the relevance of images is of high importance in the decision-making [23]. We advise its use in routine practice to force $C E$ readers to think about decision-making at the time of CE reading [24].

\section{Yano-Yamamoto classification/score}

The Yano-Yamamoto classification was originally devised for device-assisted enteroscopy (DAE), as real-time evaluation of lesion's pulsatility was a requisite for accurate classification, 
- Table 1 International Delphi Consensus on the nomenclature and descriptions of the most frequent SB vascular lesions.

\begin{tabular}{|c|c|c|}
\hline Nomenclature & Semantic description & $\begin{array}{l}\text { Nomenclature/description (\%) } \\
\text { agreement/strong agreement }\end{array}$ \\
\hline Angiectasia/angiodysplasia & $\begin{array}{l}\text { Clearly demarcated, bright-red, flat lesion, consisting of tortuous \& clus- } \\
\text { tered capillary dilatations, within the mucosal layer (surrounded by intes- } \\
\text { tinal villi). } \\
\text { Small (few } \mathrm{mm} \text { ) to large (few } \mathrm{cm} \text { ). }\end{array}$ & $100 \% / 93 \%$ \\
\hline Erythematous patch & $\begin{array}{l}\text { Small (few } \mathrm{mm} \text { ) \& flat reddish area, without any vessel appearance, within } \\
\text { the mucosal layer (surrounded by intestinal villi). }\end{array}$ & $87 \% / 80 \%$ \\
\hline Red spot/dot & $\begin{array}{l}\text { Miniscule }(<1 \mathrm{~mm}) \text {, punctuate, flat lesion with a bright-red area, without } \\
\text { linear or vessel appearance, within the mucosal layer (surrounded by villi). }\end{array}$ & $93 \% / 80 \%$ \\
\hline Phlebectasia & $\begin{array}{l}\text { Small (few mm), flat-to-slightly elevated, bluish venous dilatation running } \\
\text { below the mucosa (covered by villi). }\end{array}$ & $93 \% / 87 \%$ \\
\hline Diminutive angiectasia $^{1}$ & $\begin{array}{l}\text { Clearly demarcated, linear, bright-red lesion, consisting of tiny non-clus- } \\
\text { tered capillary dilatations, within the mucosal layer (surrounded by villi). }\end{array}$ & $73 \% / 87 \%$ \\
\hline $\begin{array}{l}\text { SB, small bowel. } \\
{ }^{1} \text { consensus was not reached }\end{array}$ & & \\
\hline
\end{tabular}

- Table 2 International Delphi Consensus on the nomenclature and descriptions of the most frequent SB inflammatory lesions.

\begin{tabular}{|l|l|l|}
\hline Nomenclature & Description & $\begin{array}{c}\text { Nomenclature/description (\%) } \\
\text { agreement/strong agreement }\end{array}$ \\
\hline Aphthoid erosion & $\begin{array}{l}\text { Diminutive loss of epithelial layering with a whitish center and a red halo, } \\
\text { surrounded by normal mucosa. }\end{array}$ & $85.2 \% / 96.3 \%$ \\
\hline Deep ulceration & $\begin{array}{l}\text { Frankly deep loss of tissue compared to the surrounding swollen/edema- } \\
\text { tous mucosa, with a whitish base }\end{array}$ & $96.3 \% / 85.2 \%$ \\
\hline Superficial ulceration & $\begin{array}{l}\text { Mildly depressed loss of tissue with a whitish bottom, whose features fit } \\
\text { neither with that of aphthoid erosion nor with that of deep ulceration, as }\end{array}$ & $81.5 \% / 85.2 \%$ \\
\hline previously defined & $\begin{array}{l}\text { Narrowing of the intestinal lumen withholding or delaying the passing of } \\
\text { the videocapsule (therefore, to be evaluated on a video) }\end{array}$ & $100.0 \% / 88.9 \%$ \\
\hline Stenosis & Enlarged/swollen/engorged villi & $85.2 \% / 81.5 \%$ \\
\hline Oedema & Area of reddish villi & $96.3 \% / 81.5 \%$ \\
\hline Hyperemia & Reddish (but not whitish) mucosal area where villi are absent & $81.5 \% / 81.5 \%$ \\
\hline Denudation & & \\
\hline SB, small bowel. & & \\
\hline
\end{tabular}

- Table 3 Saurin classification (score) of bleeding potential of lesions in MGB.

\begin{tabular}{|l|l|l|}
\hline Classification (type) & Examples & Risk of bleeding \\
\hline P0 & $\begin{array}{l}\text { Phlebectasia, erythematous patch, diverticula without the presence of } \\
\text { blood, nodules without mucosal break }\end{array}$ & No potential of bleeding \\
\hline P1 & Red spots, small or isolated erosions, possibly diminutive angiectasias & Low/uncertain \\
\hline P2 & Typical angiomas, large ulcerations, tumors, varices & High \\
\hline
\end{tabular}

being difficult to assess solely on the basis of lesion's morphology. However, this classification system of SB vascular lesions has been shown to contribute in stratifying SB lesions detected by either small bowel CE or DAE [25], based on their estimated bleeding risk. Literature data are scarce or conflicting regarding the magnitude of the risk and/or the potential benefit of endo- scopic therapy for each type of lesion [26, 27]. According to this classification system, angiectasias are considered Type 1 lesions, Dieulafoy's lesions are Type 2, and arteriovenous malformations are Type 3 ( $\triangleright$ Table 4 , $\triangleright$ Fig. 1 ).

Comment: The Saurin classification has been validated and widely adopted. It is currently recommended as the method of 
- Table 4 Yano-Yamamoto classification.

\begin{tabular}{|c|c|}
\hline Type & Description \\
\hline $1 \mathrm{a}$ & Red spot/angiectasia $<1 \mathrm{~mm}$ (with or without oozing) \\
\hline $1 \mathrm{~b}$ & Angiectasia $\geq 2 \mathrm{~mm}$ (with or without oozing) \\
\hline $2 a$ & $\begin{array}{l}\text { Dieulafoy's lesion }<1 \mathrm{~mm} \text { (punctulate lesion with pulsatile } \\
\text { bleeding) }\end{array}$ \\
\hline $2 b$ & $\begin{array}{l}\text { Dieulafoy's lesion } \geq 2 \mathrm{~mm} \text { (pulsatile red protrusion with } \\
\text { pulsatile bleeding) }\end{array}$ \\
\hline 3 & $\begin{array}{l}\text { Arteriovenous malformation (pulsatile red protrusion with } \\
\text { surrounding venous dilatation) }\end{array}$ \\
\hline 4 & Atypical/unclassifiable \\
\hline
\end{tabular}

choice for evaluating the relevance of the lesions detected by SBCE in patients with MGB. Lesions classified as P2 are considered as having high potential of clinically significant bleeding.

\section{Scores to predict the diagnosis of potentially bleeding SB lesions}

Several clinical variables have been associated with a higher diagnostic yield (DY) of SBCE for potentially bleeding lesions. A study of almost 1,000 patients with OGIB showed that age > 60 years, overt bleeding and current hospitalization were all independent predictors for identifying a bleeding source on CE [28]. In patients with suspected SB bleeding, older age, overt bleeding, low hemoglobin $(\mathrm{Hb})$ and increasing transfusion requirements have been consistently associated with the diagnosis of SB angiectasias [28-31]. Furthermore, a wide range of comorbidities were shown to associate with SB angiectasias, although results are inconsistent across studies, possibly due to significant heterogeneity in the design, population, length of follow-up, lack of standardized management or follow-up modality, and/or interobserver variability of CE interpretation.

A positive association has been described in patients with cardiovascular disease, mainly aortic stenosis (Heyde's disease) [32], heart failure with implantation of left ventricular assist device [33], ischemic heart disease [34], venous thromboembolism [35], von Willebrand's disease [36], chronic kidney disease (mainly late stages or dialyzed patients) or liver cirrhosis (mainly associated with portal hypertension) [37], among others. The use of anticoagulants and/or antiplatelet drugs has also been associated with an increased DY of SB CE, although it remains unclear whether these drugs are directly responsible for lesions' occurrence, or only contribute to the induction of bleeding from preexisting lesions, leading to the investigation and diagnosis of potentially bleeding lesions that could have remained clinically silent and undetected otherwise [38-40].

With the purpose of increasing the accuracy to predict the diagnosis of significant SB lesions in patients with suspected MGB, two scoring systems have been recently devised and are readily available for use in clinical practice: the Suspected Small Bowel Bleeding (SSB) Capsule Dx score [41] and the Ohmiya score [42]. These practical scores are expected to contribute

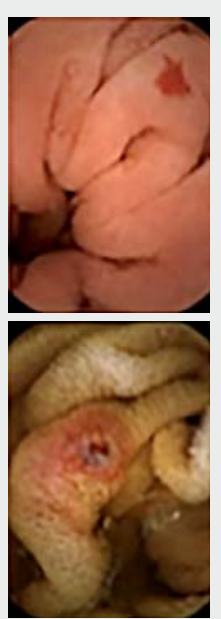

Type 1: Angiectasias

- 1a: Red spot/angiectasia <1 mm (with or without oozing)

- 1b: Angiectasia $\geq 2 \mathrm{~mm}$ (with or without oozing)

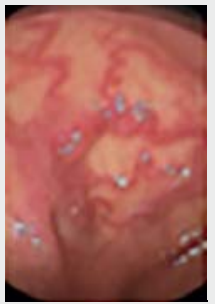

Type 2: Dieulafoy's lesions

- 2a: Dieulafoy's lesion < 1 mm (punctulate lesion with pulsatile bleeding)

- 2b: Dieulafoy's lesion $\geq 2 \mathrm{~mm}$ (pulsatile red protrusion without surrounding venous dilation)

Type 3: Arteriovenous malformations

- Pulsatile red protrusion with surrounding venous dilatation

- Fig. 1 Bleeding lesions adapted from Yano-Yamamoto Classification ( Table 4 ).

to guide the diagnostic workflow while improving patients' selection for SBCE.

\section{Suspected Small Bowel Bleeding Capsule Dx score}

A large multicenter cohort study of patients with suspected SB bleeding identified age $>54$ years, $\mathrm{Hb}<6.4 \mathrm{~g} / \mathrm{dL}$ and inpatient status with overt bleeding as independent predictors for identifying a clinically significant diagnosis on CE [41]. Subsequently, a sensitive scoring system was successfully validated, being able to contribute for the decision of limiting the use of SB CE in low-risk patients ( $\triangleright$ Table 5, $\triangleright$ Fig. 2).

\section{Ohmiya score}

Ohmiya et al. developed a weighted comorbidity index based on various comorbidities which were associated with the development of SB vascular diseases and recurrent bleeding ( Table 6, $>$ Fig. 3) [42]. The final score results of the sum of the points attributed to each of the comorbidities of the patient, varying from 0 to 22 points. The ratio of SB vascular disease to nonvascular disease increases along with the Ohmiya score $(<30 \%$ if index $<2$, and higher than $50 \%$ if index $\geq 2)$. Interestingly, when combining the age of the patient (younger or older than 50 years) and the Ohmiya index, the authors were able to further stratify the different SB haemorrhagic diseases. Indeed, onset age $\geq 50$ years and index score $<2$ identified patients with inflammatory disease, drug-induced injuries, or tumors with $72 \%$ accuracy, while an index score $\geq 2$ identified patients with SB vascular diseases with $68 \%$ accuracy, regardless of age. Furthermore, the Ohmiya score also proved to be useful 


\begin{tabular}{|c|c|c|c|}
\hline \multicolumn{2}{|c|}{ SSB Capsule Dx score } & \multirow{2}{*}{$\begin{array}{l}\text { Yes } \\
1\end{array}$} & \multirow{2}{*}{$\begin{array}{l}\text { No } \\
0\end{array}$} \\
\hline A & Patient admitted to hospital with overt bleeding & & \\
\hline B & pre-VCE hemoglobin of less than $6.4 \mathrm{~g} / \mathrm{dL}$ & 1 & 0 \\
\hline C & Age $>54$ years old & 1 & 0 \\
\hline
\end{tabular}

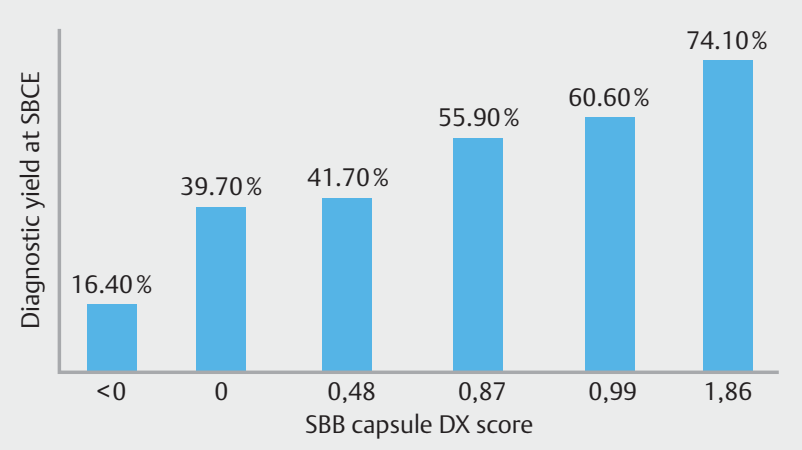

- Fig. 2 Diagnostic yield at SBCE per SSB Capsule Dx score.

> Table 6 Ohmiya Score.

\begin{tabular}{|l|l|}
\hline Condition & Scoring points \\
\hline Angina pectoris & 1 \\
\hline Arrhythmia & 1 \\
\hline Congestive heart failure & 2 \\
\hline Chronic kidney disease & 3 \\
\hline Hemodialysis & 3 \\
\hline Peripheral vascular disease & 3 \\
\hline Valvular heart disease & 3 \\
\hline Portal hypertensive disease & 3 \\
\hline Hereditary vascular disease & 3 \\
\hline
\end{tabular}

for the prediction of rebleeding: $33 \%$ of patients with scores $\geq 2$ had recurrence of bleeding, versus only $15 \%$ of patients with scores $<2$ (hazard ratio for score $\geq 2,1.729 ; 95 \% \mathrm{Cl}, 1.038$ to 2.882; $\mathrm{P}=.0355$ ).

Comment: A few scoring systems are currently available for predicting the diagnosis of SB lesions in patients with OGIB, such as the SSB Capsule Dx score and the Ohmiya score. Those scores have the potential to optimize the diagnostic algorithm and clinical management of patients with suspected SB bleeding, by prioritizing access to CE.

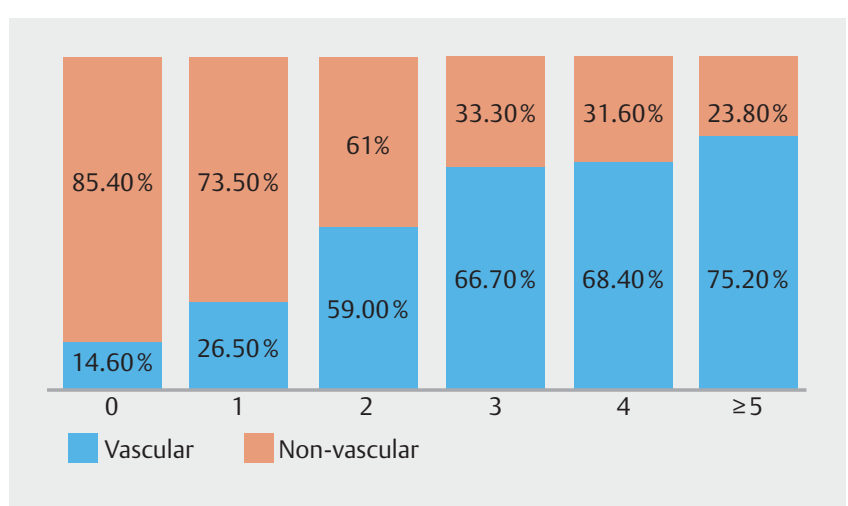

- Fig. 3 SB vascular lesions ratios (vs. non-vascular diseases) for Ohmiya comorbidity index.

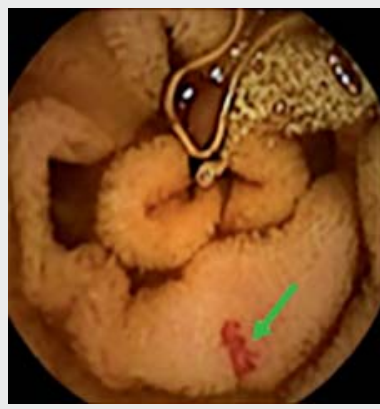

Clinical factors associated with SB angiectasias in patients with obscure GI bleeding

- Age > 60 years

- Use of anticoagulants

- Overt bleeding

- Severe anaemia $(\leq 7 \mathrm{~g} / \mathrm{dL})$

- Increasing transfusion requirements

Fig. 4 Clinical factors associated with SB angiectasias.

\section{Scores for assessing the risk of rebleeding in patients with known SB lesions}

Patients with SB angiectasias have a significant risk of rebleeding, mainly during the first 2 years after the initial event [43, 44]. Data converge to the conclusion that advanced age [ 45 , 46] and medication with anticoagulants $[47,48]$ are among the significant independent factors increasing the risk of rebleeding ( $\triangleright$ Fig. 4). There is ongoing debate on the efficacy of endoscopic treatment of SB angiectasias in reducing the risk of rebleeding $[49,50]$. A recent meta-analysis found a rebleeding rate of $45 \%$ in patients with SB angiectasias after endoscopic treatment [51], although an overall decrease in transfusion requirements has been described even for some of the patients who experience recurrence of bleeding [52-54].

Many other clinical variables have been associated with an increased risk of rebleeding, such as overt bleeding [55], low hemoglobin level with higher transfusion requirements [56, 57], CE positive findings [58,59], $\geq 3$ angiectasias $[60,61]$, lesion size [62], proximal location in the SB $[63,64]$, Yano-Yamamoto classification [25], chronic renal disease [65, 66], cirrhosis [43], cardiac disease [21,60], antiplatelet or nonsteroidal antiinflammatory drug (NSAID) use [47], among others. Besides the aforementioned Ohmiya score, other scoring systems with clinical applicability have been recently devised for this purpose, integrating and weighting many of the described poten- 
- Table 7 RHEMITT score: variables and scoring points.

\begin{tabular}{|c|c|c|c|}
\hline & $\begin{array}{l}\text { Hazard ratio } \\
\text { (Cl 95\%) }\end{array}$ & $P$ value & $\begin{array}{l}\text { Score } \\
\text { points }\end{array}$ \\
\hline Renal disease $^{1}$ & $3.1(2.0-5.0)$ & $<0.001$ & 3 \\
\hline Heart failure & $1.6(1.0-2.6)$ & 0.044 & 1 \\
\hline \multicolumn{4}{|l|}{ Endoscopic findings ${ }^{2}$} \\
\hline P1 lesions & $2.2(1.1-4.2)$ & 0.021 & 2 \\
\hline P2 lesions & $2.5(1.4-4.6)$ & 0.002 & 3 \\
\hline Major bleeding ${ }^{3}$ & $5.9(2.7-13.1)$ & $<0.001$ & 5 \\
\hline Incomplete SBCE & $2.0(1.1-3.8)$ & 0.031 & 2 \\
\hline Tobacco consumption ${ }^{4}$ & $1.9(1.2-3.1)$ & 0.006 & 2 \\
\hline Treatment (endoscopic) & $2.3(1.4-3.8)$ & 0.002 & 2 \\
\hline \multicolumn{4}{|c|}{$\begin{array}{l}1 \text { Stage } 4 \text { or } 5 \text { chronic kidney disease. } \\
2 \text { Saurin classification (only the higher rating accountable). } \\
{ }^{3} \text { Bleeding causing a fall in hemoglobin level of } \geq 2 \mathrm{~g} / \mathrm{dL} \text { or leading to trans- } \\
\text { fusion of } \geq 2 \text { units of red blood cells. } \\
{ }^{4} \geq 10 \text { cigarettes/day. }\end{array}$} \\
\hline
\end{tabular}

tial predictive factors to give a magnitude of the risk of rebleeding for each individual patient, allowing physicians to objectively stratify the risk and tailor the follow-up strategy accordingly.

\section{RHEMITT Score}

The RHEMITT score [67] demonstrated good accuracy for stratifying the risk of rebleeding in patients with MGB (area under the curve ROC $0.842,95 \% \mathrm{Cl} 0.757$ to 0.927 ). Three rebleeding risk groups were established: low (0-3 points); intermediate (4-10 points); and high (+11 points) ( $>$ Table 7, $>$ Fig. 5 ). Recently, an external validation cohort confirmed the usefulness and accuracy of the RHEMITT score in predicting rebleeding after SBCE [67]. Besides occurring more frequently, rebleeding also tends to occur earlier in intermediate (4-10 points) and high-risk patients ( $\geq 11$ points) $[67,68]$. The RHEMITT score may contribute to assist physicians in the follow-up of patients with MGB, ultimately aiming to decrease the risk of rebleeding events, by means of optimized surveillance intervals and rational allocation of resources.

\section{Predicting Rebleeding in Small Bowel Bleeding (PRSBB) Score}

Uchida et al. developed and validated a nomogram which is able to predict the risk of rebleeding and to guide a risk-stratified follow-up strategy in SB bleeding patients [69]. It is based on eight independent risk factors for rebleeding: age, sex, SBB type, transfusion requirement, cardiovascular disease, liver cirrhosis, CE findings, and treatment ( $\$$ Fig. 6). Cumulative rate of rebleeding was $3.6 \%$ for low-risk, $12.8 \%$ for intermediate-risk and $23.4 \%$ for high-risk patients ( $>$ Fig. 7). As most rebleeding events occurred within 2 years in low-risk patients and within 3 years in intermediate- or high-risk patients, the authors suggest that follow-up should be planned accordingly.

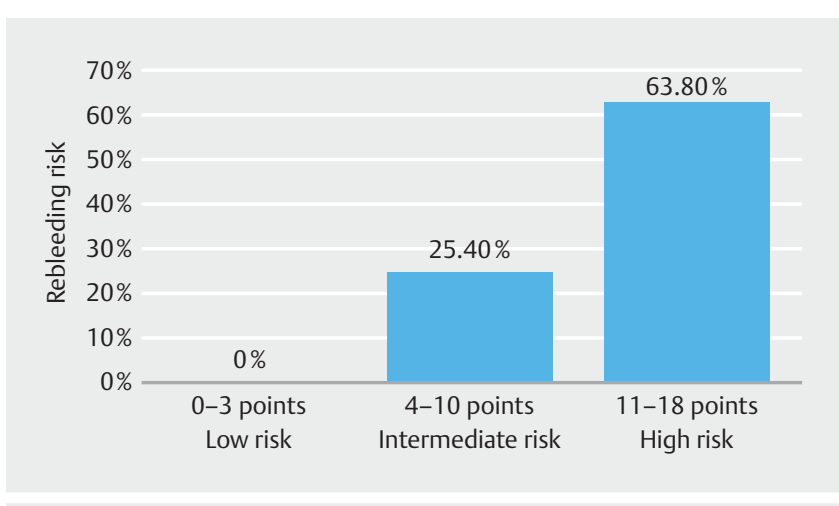

- Fig. 5 RHEMITT score: rate of rebleeding per stratification of risk.

Furthermore, the same authors developed and validated a simple scoring system to determine the necessity of doubleballoon enteroscopy (DBE) in OGIB [70], according to the stratification of rebleeding risk based on the three independent predictors, identified by multivariate logistic regression: OGIB type, blood transfusion, and CE findings. This scoring system yielded a maximum summative score of 7 points ( $\downarrow$ Table 8 ). The prediction score showed accuracy with an area under the receiver operating characteristics curve of 0.77 . The sensitivity, specificity, positive predictive value, and negative predictive value at a cut-off $\geq 2.5$ points were $72.5 \%, 74.6 \%, 72.6 \%$, and $74.5 \%$, respectively.

\section{Niikura et al. predictive model of rebleeding in OGIB}

In a large multicenter cohort study, Niikura et al. identified five potential risk factors (female gender, cirrhosis, warfarin use, overt bleeding, positive $\mathrm{CE}$ ) for rebleeding during the followup of patients with OGIB ( $>$ Table 9, $\triangleright$ Fig. 8) [71]. The cumulative incidence of rebleeding was $11.0 \%$ at 12 months and $35.3 \%$ at 60 months. The rebleeding rate was $0 \%$ in patients with no predictors and $40 \%$ in patients with four or more predictors ( $P$ $<0.01)$. Moreover, patients with all the predictors required more transfusions, longer length of stay, and mortality was higher $(P<0.01)$.

The authors considered these findings useful for decisionmaking when assessing and treating patients with OGIB in daily clinical practice, recommending as follow-up: (1) no follow-up for patients with no risk factors; (2) follow-up for 1 year at 3to 6-month intervals in patients with any of the risk factors (approximately $20 \%$ rebleeding rate at 1 year); (3) follow-up for $>1$ year at 3 - to 6 -month intervals in patients with four or more risk factors ( $40 \%$ rebleeding rate during a 1.5 -year period).

\section{ORBIT Score}

The ORBIT score was originally created to predict major bleeding in patients with atrial fibrillation and chronic anticoagulation [72]. It represents an acronym composed of five clinical variables, ranging from 0 to a maximum of 7 points, and it has been recently adapted to patients presenting with MGB submitted to CE ( $>$ Table 10, $>$ Fig.9) [73]. The mean interval of the follow-up was 35 months (range: 6 to 103 months). In highrisk patients, rebleeding was significantly more common than 


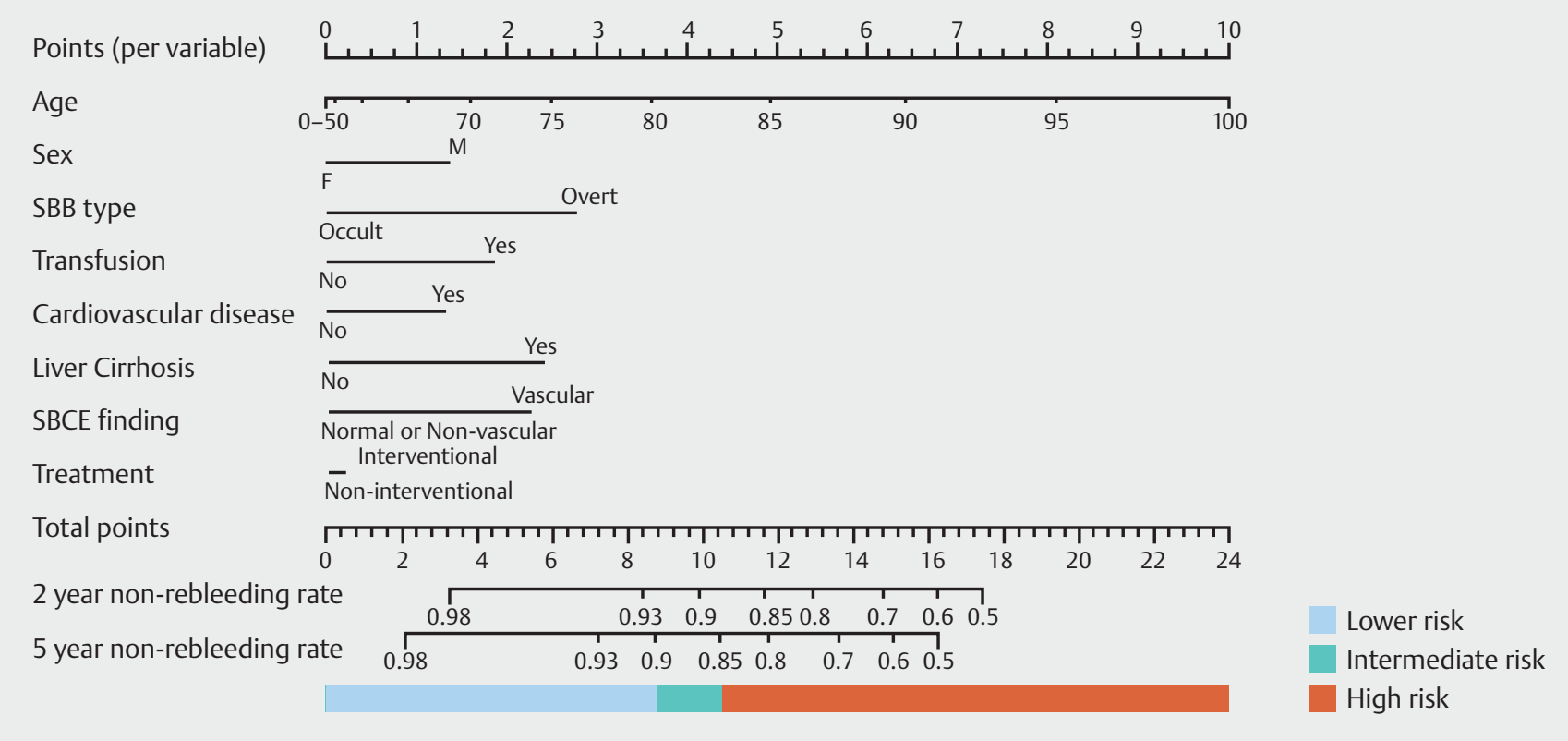

Fig. 6 PRSBB score nomogram.

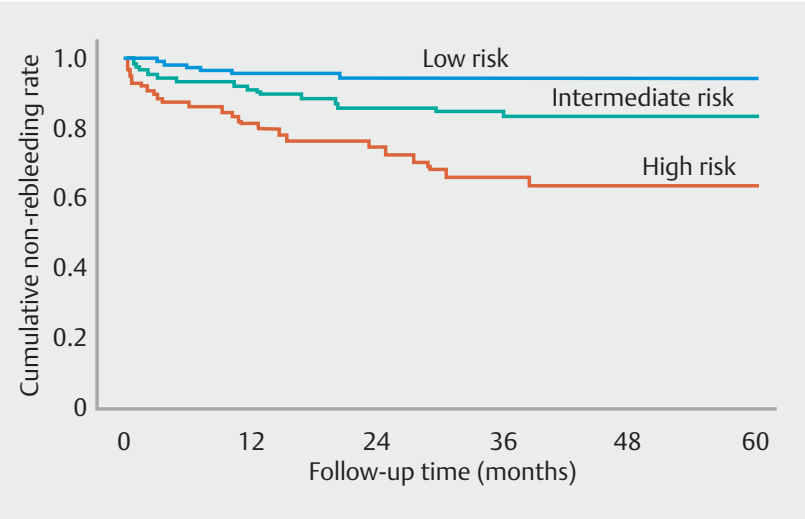

- Fig. 7 Cumulative non-rebleeding rate.

in low/intermediate-risk patients $(80.0 \%$ vs. $36.6 \%$; $P=0.003)$. The authors concluded that due to the increased risk or rebleeding, patients with an ORBIT score of 4 points or more should have a closer follow-up and proactive diagnostic and therapeutic management.

Comment: Scoring systems such as the PRSBB and, most recently, the RHEMITT score have been validated and can be used for the stratification of individuals with documented MGB as low, intermediate, or high risk of rebleeding. These scores are readily available for clinical practice while planning the followup and therapeutic approach, aiming to improve the clinical outcomes of patients with MGB.
- Table 8 Double-balloon endoscopy score.

\begin{tabular}{|l|l|l|l|l|}
\hline & $\mathbf{0}$ & $\mathbf{1}$ & $\mathbf{2}$ & $\mathbf{4}$ \\
\hline OGIB type & Occult & Previous & Ongoing & - \\
\hline Blood transfusion & No & Yes & - & - \\
\hline SBCE findings & $\begin{array}{l}\text { Normal/ } \\
\text { erosion }\end{array}$ & Ulcer & $\begin{array}{l}\text { Vascular } \\
\text { lesion }\end{array}$ & Tumor \\
\hline
\end{tabular}

Scores $0-2$ ( $52.3 \%$ of patients): low necessity of DBE

Scores $\geq 3$ ( $47.7 \%$ of patients): high necessity of DBE

OGIB, obscure gastrointestinal bleeding; SBCE, small-bowel capsule endoscopy; DBE, double-balloon endoscopy.

- Table 9 Niikura et al. predictive model: risk factors associated with clinical outcomes.

\begin{tabular}{l} 
Risk factors $(\mathbf{n})$ \\
\hline Female gender \\
\hline Cirrhosis \\
\hline Warfarin use \\
Overt bleeding \\
\hline Positive SBCE \\
SBCE, small-bowel capsule endoscopy \\
\hline
\end{tabular}

\section{Lesion localization indices}

When a lesion is detected by $C E$, choosing the optimal insertion route for DAE is a pivotal step in patient management. The correct choice helps to minimize the number of endoscopic examinations with no or limited yield and provides a cost-effective \& 


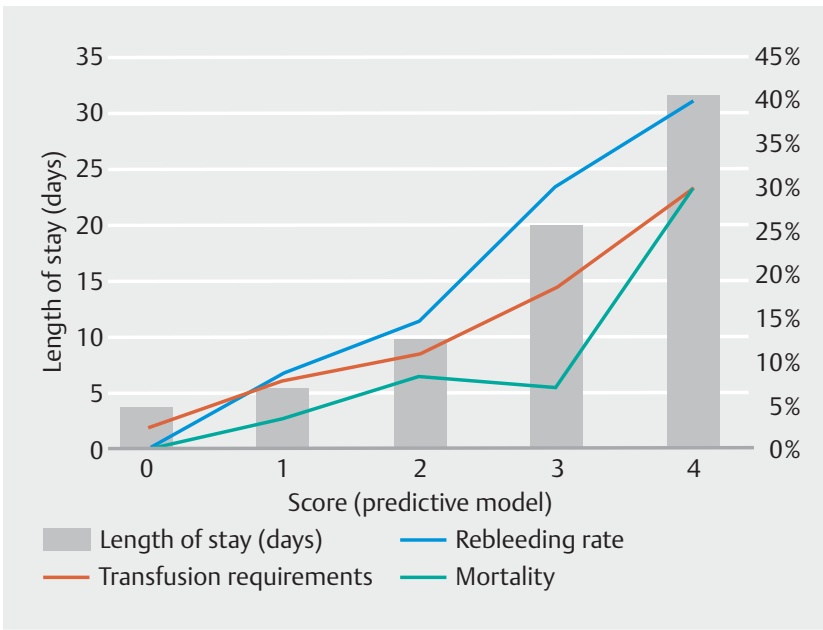

- Fig. 8 Niikura et al. predictive model: association with clinical outcomes.

precision approach $[15,74-76]$. The location of a lesion in the SB can be estimated by CE time-based indices, expressed as the time taken for the capsule to reach the lesion divided by the examination's total transit time (TT). Some software modes show the percentage of SB TT for each image ( $\mathbf{F i g} .10$ ). Additional Al-tools as progression indicator aim to modify the timebased calculation into a SB length-estimation by including measurement of capsule movement. This can lead to quit divergent TT intervals corresponding to length-based tertil-calculation. If a graphic localization image is also available, areas of evident delay in transit can be counter-checked and taken into account for planning enteroscopy access.

Eventually, the choice of the route of insertion is based on a specific cut-off, decided a priori by the team: if the lesion is detected within this cut-off the approach will be antegrade, and conversely. But which is the most reliable cut-off? Several studies have been conducted on this premise, mainly differing in the DAE technique used and the CE landmarks that are taken into consideration.

The concept of CE TT in DAE insertion route selection was first analyzed by Gay et al. [76], using an index based on the time from capsule ingestion to caecum, with a ratio cut-off of 0.75 . When the lesion was located at $\geq 75 \%$ of the total TT, the positive predictive value (PPV) and negative predictive value (NPV) for a retrograde approach were $94.7 \%$ and $96.7 \%$, respectively. The main limitation of this index is the inherent variability of the gastric TT. To overcome this, subsequent studies took into account the TT from the pylorus (or the first duodenal image) to the caecum (or ileocecal valve). A cut-off of 0.5 was proposed by Nakamura et al. [77] and Maeda et al. [78], whereas Li et al. [79] and Lin et al. [80] proposed a cut-off of 0.6 and 0.66 , respectively. According to Chalazan et al. [81] the best-performing cut-offs for antegrade and retrograde DAE were 0.57 and 0.74 , respectively. Furthermore, Tsuboi et al. [82] validated the role of the integrated PillCam Progress indicator a progression-based index, used with a cut-off of 0.5 . It
- Table 10 ORBIT score: risk of rebleeding in patients with suspected mid-gastrointestinal bleeding under chronic anticoagulation.

\begin{tabular}{|c|c|}
\hline & Points assigned \\
\hline Older age ( $\geq 75$ years) & 1 \\
\hline Reduced hemoglobin ${ }^{1}$ & 2 \\
\hline Bleeding history ${ }^{2}$ & 2 \\
\hline Insufficient renal function ${ }^{3}$ & 1 \\
\hline Treatment with antiplatelets ${ }^{4}$ & 1 \\
\hline \multicolumn{2}{|c|}{$\begin{array}{l}{ }^{1} \text { Hemoglobin }<12 \mathrm{~g} / \mathrm{dL} \text { for women or }<13 \mathrm{~g} / \mathrm{dL} \text { for men or hematocrit }<36 \% \\
\text { for women or }<40 \% \text { for men. } \\
{ }^{2} \text { Any history of gastrointestinal bleeding or intracranial bleeding, i. e., epi- } \\
\text { dural hematoma, subdural hematoma, subarachnoid haemorrhage, or in- } \\
\text { tracerebral or intraventricular hemorrhage. } \\
{ }^{3} \text { Estimated glomerular filtration rate }<60 \mathrm{mg} / \mathrm{dL} / 1.73 \mathrm{~m}^{2} \text {. } \\
{ }^{4} \text { Aspirin, ticagrelor, prasugrel, clopidogrel or fixed-dose combination aspir- } \\
\text { in-dipyridamole. }\end{array}$} \\
\hline
\end{tabular}

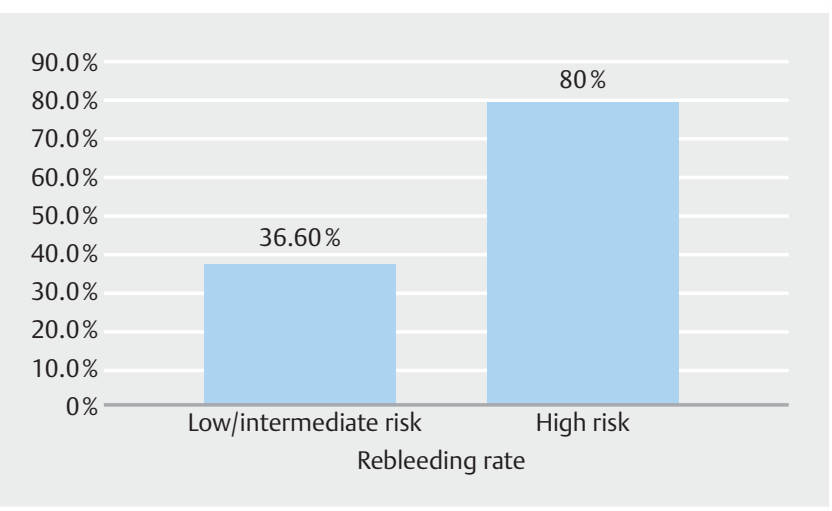

- Fig. 9 ORBIT score: rate of rebleeding per risk stratification.
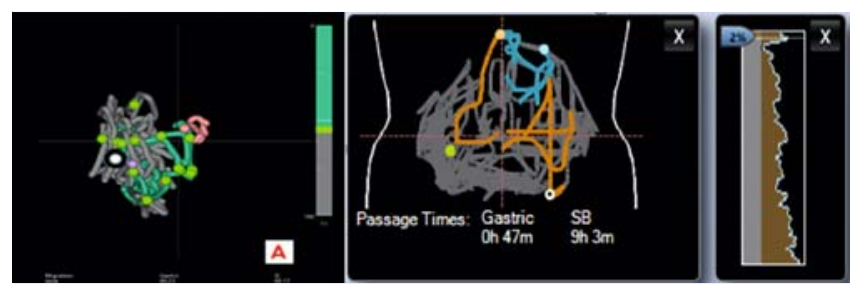

- Fig. $103 \mathrm{D}$ localization trace with SB in green. Bar on the right presents the SB length travelled. 2D localization trace showing capsule passing the duodenum and reaching the proximal jejunum. On the right, similarity of images (corresponding to low speed) is increasing (higher amplitudes) towards the distal SB. Percentage of transit is displayed.

is worth noting that DBE was the chosen DAE technique in all of these studies.

Although the proposed cut-offs differ slightly, in terms of SB percentage, they all had acceptable performances with the following success rates: Li et al., 100\%; Lin et al., 100\%; Maeda et al., 78.3\%; Tsuboi et al., 96\%. PPV and sensitivity were $97 \%$ and $90 \%$ in the study by Nakamura et al., whereas Chalazan et al. reported $75 \%$ and $75 \%$ for antegrade approach and $78 \%$ and $88 \%$ for retrograde approach. Recently, Mandaliya et al. [83] con- 


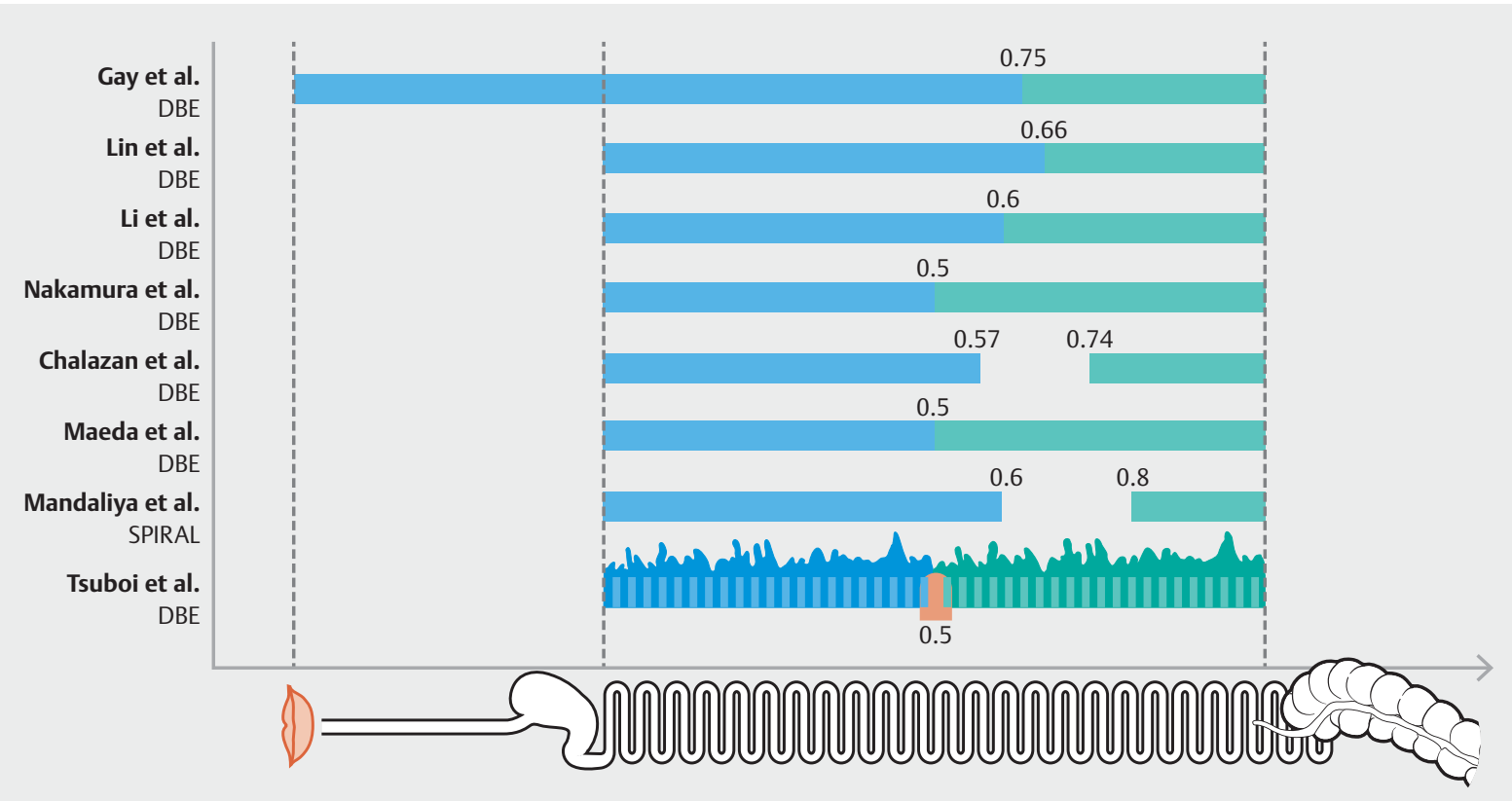

Fig.11 A graphical representation of the transit time- and progression-based localization scores.

firmed the usefulness of a capsule lesion index with spiral enteroscopy (SE), using the first duodenal image and the first cecal image as landmarks. Antegrade and retrograde SE were performed with index $<0.6$ and $>0.8$, respectively: for lesions in between 0.6 and 0.8 an individualized approach was suggested. A clear schematic overview of the indices is shown in > Fig. 11.

Comment: Although tested indices may differ in cut-offs and landmarks, their overall outcomes are highly successful. An SB TT $<50 \%$ clearly favors antegrade approach for DBE, and $>75 \%$ a retrograde approach, respectively. Divergent results between these thresholds reflect the difficulty of reaching the mid-SB and warrant an individual approach. To note, in doubtful cases (e.g., the lesion is located spot at the cut-off value) the antegrade approach is the one to be preferred, for both technical and clinical reasons.

\section{Inflammatory scores in CE}

$C D$ can affect the entire gastrointestinal tract. The extent and severity of SB inflammation can be assessed with computed tomography enterography, magnetic resonance enterography, intestinal ultrasound (US) and/or CE. CE is considered the most sensitive of these modalities with a particular advantage in evaluating proximal SB mucosal involvement [84]. Other causes of SB inflammation include NSAIDs-induced enteropathy, coeliac disease with ulcerative jejuno-ileitis, lymphoma, radiation enteritis, opportunistic infections, intestinal tuberculosis, HIV, and Bechet's disease [85].

There are different ways to measure the response of inflammation to different treatments. Endoscopic measures of inflammation, for example, the CD Endoscopic Index of Severity or the simple endoscopic index of severity, take into account parameters like deep or superficial ulcerations and their surface, but these scores can only assess areas that are within the reach of the colonoscope, i. e. colon and terminal ileum. The invention of CE introduced the need for quantitative metrics to assess mucosal inflammation. Furthermore, as treatment targets focus on the importance of mucosal healing, this has become even more essential. Several quantitative inflammatory scores for CE have been developed over the years, some for SB only and some for both SB and the colon.

\section{Inflammatory scores SB CE}

\section{Lewis score}

The so-called Lewis score (LS) was the first inflammatory score that was introduced and is the most widely used index, as it is embedded in the CE RAPID software (Medtronic, United States). In this, SB is artificially divided into three parts according to the TT (from the first duodenal image to the first caecal image), so that three tertiles are obtained. The division, however, is on an artificial basis; these tertiles are actually determined by time and not by SB length, thus allowing proximal tertiles more pronunciation if the capsule stays for a long time in the ileum/terminal ileum. New software algorithms aim to modify the tertiles by including capsule movement calculation ( $>$ Fig. 12). For each of the tertiles, there is a scoring index that includes three endoscopic variables: villous edema, ulcerations and stenosis. Index parameters are measured by number (none, single, few 2-7, multiple i.e. $\geq 8$ ), longitudinal extent (short segment $<10 \%$, long segment $10-50 \%$, whole tertile $>50 \%$ ) and additional descriptors (circumferential extent, etc.) ( $\triangleright$ Table 11 and $>$ Fig. 13). 


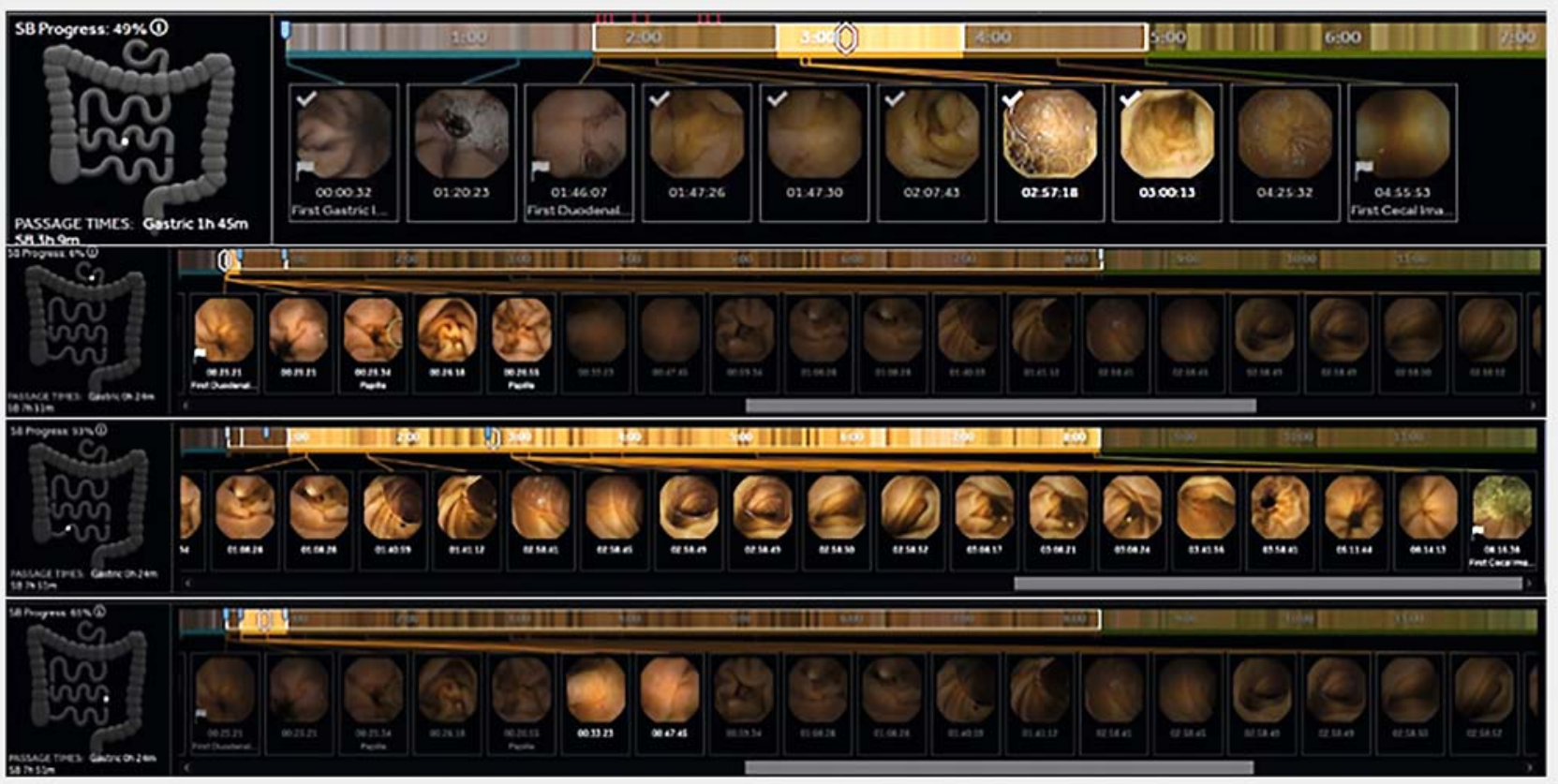

- Fig. 12 SB divided into three tertiles (top image). Al-assisted division of SB into three tertiles of estimated equal length, corresponding to very different transit times each: proximal SB (upper row), mid SB (lower row), and distal SB (middle row). On the left of each row, a white point presents the localization of the capsule in a pictogram solely as estimated by modified transit time.

The score is calculated separately for each tertile and the final score is the highest of the three. A score $<135$ is designated normal or clinically insignificant mucosal inflammatory change; a score of $\geq 135-<790=$ mild inflammation; and, $\geq 790=$ moderate-to-severe inflammation [86]. The score was validated by showing a strong inter-observer agreement for the determination of the LS in a monitoring established CD [87]. LS was found to be effective both in diagnosing CD and assessing the extent of the disease and in monitoring and evaluating response to treatment. In a retrospective study, CD was ultimately diagnosed in $82.6 \%$ of patients with significant inflammatory activity on CE (LS>135), but in just $12.1 \%$ of those having a $L S<135$ $(P<0.05)$. The PPV, NPV, sensitivity and specificity were $82.6 \%$, $87.9 \%, 82.6 \%$, and $87.9 \%$, respectively [88]. Another study included patients who underwent CE for suspected CD according to the criteria of the International Conference on Capsule Endoscopy (ICCE) [89]. LS (cut-off>135) showed a good diagnostic accuracy of $C D$, with an area under the curve of the receiver operating characteristic (AUROC) of $0.93(P<0.001)$. There was a significant association between a higher LS and the need for immunomodulatory therapy, biological therapy, bowel resection surgery or hospital admission due to a $C D$ flare-up within the first year after diagnosis.

In a recent study on $C D$ patients in remission, different measures were examined, in their ability to predict flare-ups. Quantitative assessment of SB inflammation on CE was the most accurate predictor of relapse within 2 years, i. e. a baseline LS > 350 points predicted imminent disease exacerbation within 6 months to 2 years [90].

\section{Capsule Endoscopy Crohn's Disease Activity Index (CECDAI)/Niv score}

The score divides the SB into proximal and distal segments according to the midpoint of SB TT. Each segment is rated on the basis of three parameters, each rated on a scale of 0 to 3 or 5 points: A - inflammation (erythema, hyperaemia and edema, denudation, nodularity, aphthae, erosion, ulcer and bleeding); B - extent of disease (focal, patchy and diffuse); C - presence of narrowing (single-passed, multiple passed and obstruction). The segmental score is calculated by multiplying the inflammation sub score by the disease extent sub score and adding the stricture sub score $(A X B+C)$; the final score is calculated by adding the two segmental scores: total $\mathrm{CECDAI}=(\mathrm{A} 1 \mathrm{X} \mathrm{B} 1+$ $C 1)+(A 2 \times B 2+C 2)$ [91] ( Table 12). In 2012, the score has been validated later on by in a multicenter study led by the same group [92].

Several studies compare CECDAI to the LS. Two retrospective studies found significant correlation between LS and CECDAI (rs values of 0.6324 and $0.878, P<0.0001)[93,94]$. In a prospective study of patients with established $C D$ in clinical remission, moderate correlation between the worst segment LS and CECDAl was demonstrated (Pearson's $r=0.66, P=0.001$ ), while a stronger correlation was found between the cumulative LS and CECDAI ( $r=0.81, P=0.0001$ ) [95]. Interestingly, these studies defined very different threshold levels of CECDAI; in the retrospective studies mentioned above, CECDAI level of 3.8 and 7.7 corresponded to LS threshold of $135[93,95]$ and CECDAI level of 5.8 and 10.3 corresponded to LS threshold of 790 [93, 95]. In the latter prospective study, CECDAI level $<5.4$ corresponded to 
- Table 11 Lewis score parameters and descriptors.

\begin{tabular}{|c|c|c|c|c|c|c|}
\hline \multicolumn{7}{|c|}{ Rated for each tertile } \\
\hline Parameters & \multicolumn{2}{|l|}{ Number } & \multicolumn{2}{|c|}{ Longitudinal extent } & \multicolumn{2}{|l|}{ Descriptors } \\
\hline \multirow[t]{3}{*}{ Villous appearance } & Normal & 0 & Short segment & 8 & Single & 1 \\
\hline & Edematous & 1 & Long segment & 12 & Patchy & 14 \\
\hline & & & Whole tertile & 20 & Diffuse & 17 \\
\hline \multirow[t]{4}{*}{ Ulcer } & None & 0 & Short segment & 5 & $<1 / 4$ & 9 \\
\hline & Single & 3 & Long segment & 10 & $1 / 4-1 / 12$ & 12 \\
\hline & Few & 5 & Whole tertile & 15 & $>1 / 2$ & 18 \\
\hline & Multiple & 10 & & & & \\
\hline \multicolumn{7}{|c|}{ Stenosis - rated for whole tertile } \\
\hline & None & 0 & Ulcerated & 24 & Traversed & 7 \\
\hline & Single & 14 & Non-ulcerated & 2 & Not traversed & 10 \\
\hline & Multiple & 20 & & & & \\
\hline
\end{tabular}

Lewis score: Score of the worst-affected tertile [(villous parameter $\times$ extent $\times$ descriptor $)+($ ulcer number $\times$ extent $\times$ size $)]+$ stenosis score $($ number $\times$ ulcerated $\times$ traversed).

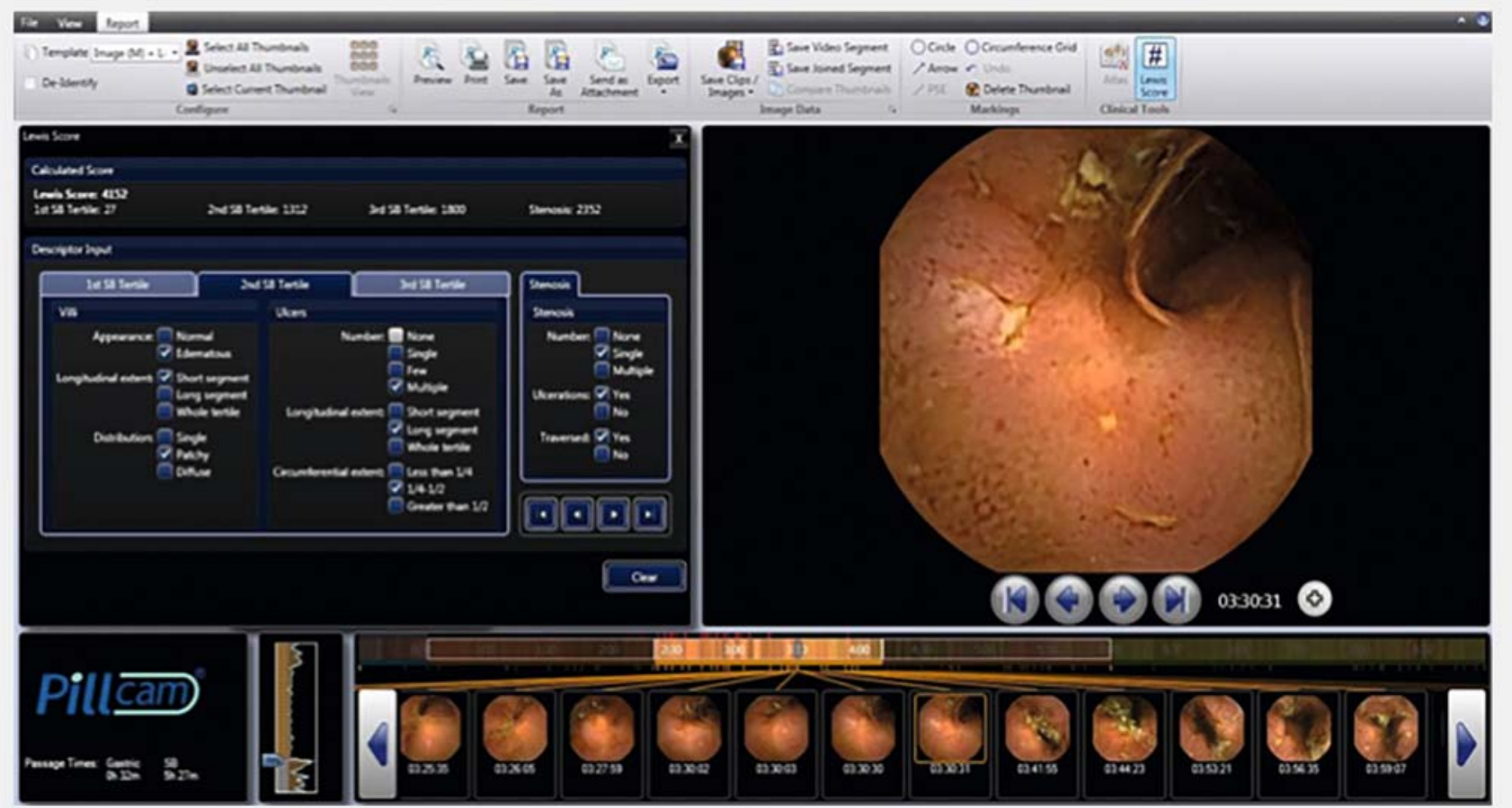

Fig. 13 Lewis score (LS) calculator, integrated in the PillCam RAPID reader.

LS < 135, while CECDAI > 9.2 corresponded to LS > 790 [94]. Thus, while the threshold values of the LS are constant, the threshold values of the CECDAI score are different among different studies, making it difficult to interpret and to clinically correlate [93-95].

Correlation between CE findings and clinical indices or laboratory biomarkers is moderate, and this is reflected in the correlation to the inflammatory scores. For example, in a retrospective study, neither $C$-reactive protein (CRP), nor the Harvey Bradshaw Index correlated with LS ( $r s=0.068, P=0.72$; $r s=$ $-0.15, P=0.40$ ) or CECDAI ( $r s=0.004, P=0.98$; $r s=0.10, P=$ 0.23) [95]. Another study demonstrated a moderate correlation between LS and fecal calprotectin (FC) $(r=0.44)$ becoming more evident in patients with FC of $100 \mathrm{mg} / \mathrm{g}(r=0.67)$. No cor- 
- Table 12 Capsule endoscopy Crohn's disease activity index (CECDAI) scoring system.

\begin{tabular}{l|l|}
\hline A. Inflammation score & 0 \\
\hline - None & 1 \\
\hline - Mild to moderate edema/hyperemia/denudation & 2 \\
\hline - Severe edema/hyperemia/denudation & 3 \\
\hline - Bleeding, exudate, aphthae, erosion, small ulcer $(>0.5 \mathrm{~cm})$ & 4 \\
\hline - Moderate ulcer (0.5-2 cm), pseudopolyps & 5 \\
\hline - Large ulcer (>2 cm) & \\
\hline B. Extent of disease score & 0 \\
\hline - None & 1 \\
\hline - Focal disease (single segment) & 2 \\
\hline - Patchy disease (multiple segments) & 3 \\
\hline - Diffuse disease & \\
\hline C. Narrowing (stricture) & 0 \\
\hline - None & 1 \\
\hline - Single-passed & 2 \\
\hline - Multiple-passed & 3 \\
\hline - Obstruction & \\
\hline Segmental score: AxB + C & \\
\hline Total score: (A1xB1+C1)+(A2xB2+C2) & \\
\hline
\end{tabular}

relation with FC was demonstrated for CECDAI [93]. In a prospective study, there was a moderate correlation between $C E$ scores and FC levels $(r=0.39, P=0.002$ for $L S, r=0.48, P=0.001$ for Cumulative LS, and $r=0.53, P=0.001$ for CECDAI, respectively). CRP levels were not significantly correlated with either score [94]. In the largest retrospective study to date, a poor correlation between LS and FC was reported $(r=0.16)$ [96].

There were other attempts to create scoring indices specifically for use with CE: Buchman et al graded CE videos as grade 0 (normal); grade 1 (erythema, isolated villi loss); grade 2 (erosion, no ulcer); or grade 3 (ulcers, spontaneous bleeding and/ or stricture). The study was undertaken to determine the accuracy of $C E$ in the diagnosis of $C D$ relative to small bowel followthrough (SBFT) and clinical/laboratory indices of CD activity. It was done by evaluation of the occurrence of active disease in patients with known CD. CE and SBFT scores highly correlated $(r=0.65, P=0.001)$. Neither CE nor SBFT scores correlated with biological or clinical indices [97]. Graham et al. assessed SB mucosal inflammation in patients taking NSAIDs. Lesions were described as red spots, small erosions, large erosions or ulcers. They defined mild injury as few or no erosions, and absence of large erosions/ulcers. Major injury was defined as $>4$ erosions or large erosions/ulcers) and provided endoscopic evidence that SB mucosal injury is very common among chronic NSAIDs users (> Table 13) [98].
- Table 13 Pros and cons of Lewis score and CECDAI.

\begin{tabular}{|l|l|l|}
\hline \multirow{2}{*}{$\begin{array}{l}\text { Lewis } \\
\text { score }\end{array}$} & Pros & Cons \\
\cline { 2 - 3 } & Validated & Segments not accurate (by time) \\
\hline \multirow{2}{*}{ EECDAI } & Software & $\begin{array}{l}\text { Score strongly influenced by stric- } \\
\text { ture }\end{array}$ \\
\hline \multirow{2}{*}{ Easy to use } & \\
\hline & Validated & Segments not accurate (by time) \\
\hline & $\begin{array}{l}\text { Comparable to } \\
\text { Lewis score }\end{array}$ & Not embedded in software \\
\hline & $\begin{array}{l}\text { Can be used for } \\
\text { colon as well }\end{array}$ & $\begin{array}{l}\text { Score strongly influenced by stric- } \\
\text { ture }\end{array}$ \\
\hline
\end{tabular}

\section{SB \& colon inflammatory scores}

\section{Capsule Endoscopy Crohn's Disease Activity Index (CECDAlic/Niv score) for SB and colon}

An extension of CECDAI or Niv score was published in 2018. It is based on the same parameters and the same calculations as in the SB with the addition of two colonic segments, proximal and distal, a total of four segments. The range of CECDAlic score is between 0 and 72 [99]. This score was examined and validated demonstrating excellent agreement between three observers. In addition, a very good correlation between CECDAlic and calprotectin $\left(r_{\mathrm{s}}=0.82 ; P=.012\right)$ and a moderate correlation with Creactive protein $\left(r_{\mathrm{s}}=0.50 ; P=.019\right)$ was shown [100].

\section{Panenteric Crohn's Capsule Score (PCCS)/Eliakim Score (ES)}

Recently, a novel pan-enteric capsule, PillCam Crohn's (Medtronic, United States), was approved for use. It allows a comprehensive view of the whole intestine [101]. In this score the whole bowel is divided by length into five segments; the small intestine is divided into three tertiles and the colon is divided into two: right colon and left colon. The score takes use of the new Crohn's specific software (Rapid 9) of the new capsule. The score is calculated separately for each segment using the following parameters: A - the most common lesion (graded by severity as $1-3$ ), $B$ - the most severe lesion (graded by severity as $1-3), C$ - approximated disease extent ( $0 \%, 0 \%$ to $10 \%, 10 \%$ to $30 \%, 30 \%$ to $60 \%, 60 \%$ to $100 \%$ ), and D - stricture. The score is calculated separately for each one of the five segments: Segmental score $((A+B) \times C)+D(\triangleright$ Table 14$)$. The final score is calculated by adding the five segmental scores. The score for the three segments of the small intestine was calculated separately by adding them to create the Small bowel PCC (PCCS-SB) score. It was compared to LS and a strong correlation $(r=0.8$ for reader 1 and $r=0.82$ for reader $2, P<0.001$ for both) was found between the scores. The calculation of the cut-off values is LS 135 $=4$, LS $350=5$, LS $790=8$ [102].

A final overview of the aforementioned scores is presented in $>$ Table 15. 
- Table 14 PillCam Crohn's disease capsule score.

A. Most common lesion (MCL)

\begin{tabular}{|l|l|}
\hline - None & 0 \\
\hline - Mild & 1 \\
\hline - Moderate & 2 \\
\hline - Severe & 3 \\
\hline B. Most severe lesion (MSL) & \\
\hline - None & 0 \\
\hline - Mild & 1 \\
\hline - Moderate & 2 \\
\hline - Severe & 3 \\
\hline C. Extent of disease & \\
\hline - None & 0 \\
\hline - $0-10 \%$ & 1 \\
\hline - $10-30 \%$ & 2 \\
\hline - 30-60\% & 3 \\
\hline - $60-100 \%$ & 4 \\
\hline
\end{tabular}

\begin{tabular}{l|l}
\hline D. Stricture & 0 \\
\hline - None & 1 \\
\hline - One traversed & 2 \\
\hline - >1 traversed & 3 \\
\hline
\end{tabular}

Segmental score: $(A+B) \times C)+D$

SB PCC (PCCS-SB): SB1 + SB2 + SB3

Panenteric PCC (PCCS):SB1 + SB2 + SB3 + RC + LC

SB, small bowel; PCCS, panenteric Crohn's capsule; RC, right colon; LC, left colon.
Aside CECDAlic, all other descriptions or scores combining small \& large bowel are not yet validated and currently should be used for research purposes only.

\section{Scores to differentiate between SB mass or innocent mucosal bulge}

Paradoxically, CE which is highly sensitive for millimetric mucosal breaks may overlook large masses, in particular in the proximal SB. A retrospective, single-center study showed a near $17 \%$ missing rate for tumors [103], in line with the first report of the low sensitivity of CE for masses [104]. An explanation of this paradox may be that a large mass, near the ligament of Treitz, exercise gravitational traction on the mobile bowel loop, hiding behind a fold, and stretching the proximal loop, so the capsule may assume a straight direction seeing it only tangentially ( Fig. 14).

There may be diagnostic confusion between a subepithelial mass and an innocent bulge (IB), bearing in mind that most of the sporadic benign and malignant tumors of the SB are subepithelial. IB is defined as a smooth, round protrusion of a normal-appearing mucosa, having an ill-defined boundary with the surrounding mucosa and a base larger than its height [105]. It is likely formed by the compression of an adjacent loop of the bowel tangle, and it is reported in up to $5 \%$ of consecutive CE $[105,106]$. A subepithelial mass devoid of alarm features (i.e. ulcer, congestion, erosion, erythema, blood, clots) looks like an IB. To discriminate a subepithelial mass from an IB, SPICE (Smooth Protruding lesion Index at Capsule Endoscopy, ( $\triangleright$ Table 16) criteria have been developed and validated in a single-center, prospective study; a SPICE score $>2$ had sensitivity $83.3 \%(95 \% \mathrm{Cl} 36$ to 99$)$ and specificity $86.4 \%$ ( $95 \% \mathrm{Cl} 67$ to 98 ) for subepithelial mass (AUROC 0.9; $95 \% \mathrm{Cl}$ 0.72 to 0.98 ) [105]. SPICE score was independently validated in two subsequent studies ( $\triangleright$ Table 17 ). Hatem et al, in a prospective series of 640 consecutive $C E$, found 30 patients with equivocal findings between IB and subepithelial mass. After diagnostic workup, three tumors were found; two of these (a car-

- Table 15 Summary of inflammatory scores.

\begin{tabular}{|l|l|l|}
\hline & SB & SB and colon \\
\hline Lewis score & + & - \\
\hline & $86,87,88,90^{1}$ & - \\
\hline Capsule Endoscopy Crohn's Disease Activity Index (CECDAI)/Niv score & + & - \\
\hline $\begin{array}{l}\text { Capsule Endoscopy Crohn's Disease Activity Index (CECDAlic/Niv Score) for the small } \\
\text { bowel and colon. }\end{array}$ & + & + \\
\hline \begin{tabular}{l} 
Panenteric Crohn's capsule score (PCCS)/Eliakim score \\
\hline
\end{tabular} & $91,92^{1}$ & + \\
\hline \begin{tabular}{l} 
Capsule Scoring of Ulcerative Colitis (CSUC) \\
\hline
\end{tabular} & + & $+100^{1}$ \\
\hline $\begin{array}{l}\text { SB, small bowel. } \\
\text { Reference number }\end{array}$ & - \\
\hline
\end{tabular}


cinoid and an ovarian metastasis) had a SPICE score $>2$ [106]. Rodrigues et al, in a retrospective series of 30 patients having a round, smooth protruding lesion, found 12 tumors; SPICE >2 showed a $66,7 \%(95 \% \mathrm{Cl} 34,9$ to 90$)$ sensitivity, $100 \%(95 \% \mathrm{Cl}$ 81,5 to 100 ) specificity, (AUROC $100 ; 95 \% \mathrm{Cl} 81,5$ to 100) [107].

More recently, Min et al - based on the fact that angle between the protrusion and the surrounding mucosa (corresponding to the first of SPICE criteria) is crucial in the differential diagnosis - calculated this angle with a protractor upon the computer screen on a retrospective series of SBCE. Twenty-five of 34 patients had a pathologic diagnosis of a tumor. In comparison with SPICE criteria, an angle lesser than 90 degrees had the same specificity but a higher sensitivity ( $92 \%$ vs $32 \%$ ) in their series [108]. In this study, the final diagnostic assessment of patients diagnosed as IB, and the length of follow-up were unclear. However, there is little doubt that quantification with a protractor of the first SPICE criterion may be useful to reduce its subjectivity and interobserver variability. Further studies, using a protractor to better define the first SPICE criterion, using a cut-off $<90^{\circ}$ to assign 1 point to the final score, are warranted.

Another score, named herein Shyung score [109], was proposed by Shyung et al, in a retrospective study comprising 12 CE in patients (age range: 23 to 79 years) with suspected SB tumors. The features of the scoring system are summarized in - Table 18. With a total score $\geq 4$, the probability of SB mass lesions was high and in this small cohort, patients had ileal ectopic pancreas, melanoma, gastrointestinal lymphoma, and gastrointestinal stromal tumor. The probability of SB mass lesions in those with a score of $\leq 2$ was low. Shyung score has not been validated in any other study.

Comment: The SPICE score has been validated as a reliable and practical tool for differentiating between innocent bulges (score $\leq 2$ ) and subepithelial masses (score $>2$ ) in SBCE.

\section{Cleanliness scores}

\section{SB CE cleanliness scores}

As in traditional endoscopy, the quality of mucosal visualization and thus the DY of CE is dependent on the absence/presence of air bubbles, bile and intestinal debris. The evaluation of the quality of SB preparation is necessary to assess the accuracy of the findings in CE. During colonoscopy, the validated Boston Bowel Preparation Score provides an assessment of colon cleanliness [110]. Several scores assessing SB cleanliness have been proposed. These can be divided into operator-dependent or automated scores. The presence of a universal grading score would also contribute to standardize CE protocols and to compare the results of different methods of small-bowel preparation.

\section{Automated scores}

Apart from having an objective, reliable, and reproducible scoring system, performing this analysis in a timely manner is also important. Thus, computer generated scores could fulfill all these criteria ( $\triangleright$ Table 19$)$ [111].

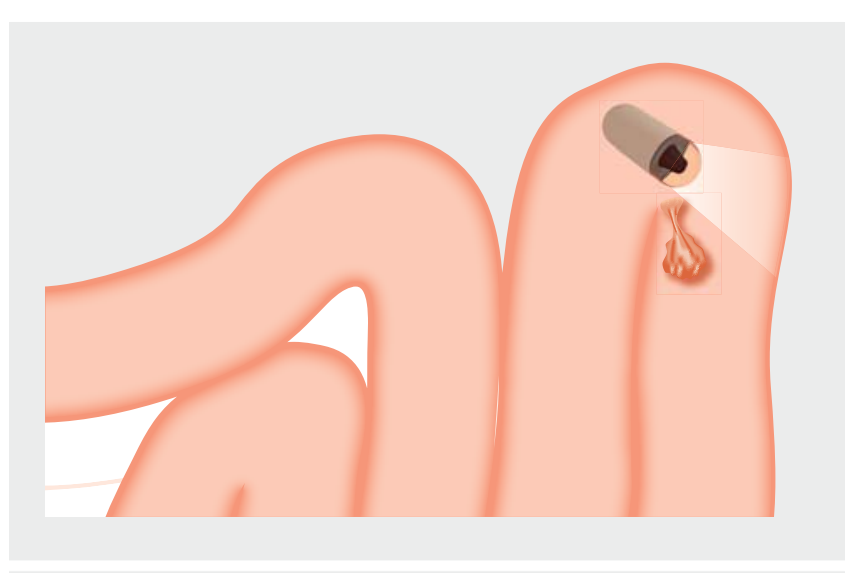

- Fig. 14 Hypothetical mechanism by which a large mass may be missed on capsule endoscopy.

- Table 16 SPICE score calculation ${ }^{1}$

\begin{tabular}{|l|c|c|}
\hline SPICE score & \multicolumn{2}{|c|}{ Score } \\
\hline Criterion & No & Yes \\
\hline III-defined boundary with the surrounding mucosa & 1 & 0 \\
\hline Diameter larger than its height & 1 & 0 \\
\hline Visible lumen in the frames in which it appears & 0 & 1 \\
\hline Image of the lesion lasting $>10$ minutes & 0 & 1 \\
\hline $\begin{array}{l}\text { SPICE, Smooth Protruding lesion Index at Capsule Endoscopy. } \\
\text { 1 A value }>2 \text { is predictive of subepithelial mass. }\end{array}$ \\
\hline
\end{tabular}

- Table 17 Summary of studies.

\begin{tabular}{|l|l|r|r|}
\hline & & SB lesions & IB \\
\hline Girelli et al & SPICE score & 6 & 19 \\
\hline Rodrigues et al & SPICE score & 12 & 18 \\
\hline Shyung et al & Shyung score & 6 & 6 \\
\hline Min et al & Mucosal protrusion angle & 25 & 9 \\
\hline
\end{tabular}

SB, small bowel; IB, innocent bulge; SPICE, Smooth Protruding lesion Index at Capsule Endoscopy

Van Weyenberg et al developed a proof of concept, computed assessment of cleansing (CAC) score, based on objective measurements of color intensities of the red over green (R/G) channels of the tissue color bar of the Rapid Reader in the PillCam CE system. This bar comprises the summary of all CE images. This was converted to the red-green-blue mode (RGB) and the relation between the mean intensity of the red and green channels was used as a measure of small-bowel cleanliness. The concept of $R / G$ ratio is based on the fact that properly visible mucosa is associated with red colors whereas a fecal-contaminated lumen is associated with green. The mean intensity values of the green and red channels were determined using a histogram function of photo editing software [111]. This ap- 
$\checkmark$ Table 18 Shyung score.

\begin{tabular}{|l|l|l|l|l|l|}
\hline Criterion & Bleeding & MD & IS & Colour & WV \\
\hline & Yes/No & Yes/No & Yes/No & Yes/No & Yes/No \\
\hline $1 / 0$ & $1 / 0$ & $1 / 0$ & $1 / 0$ & $1 / 0$ \\
\hline MD, mucosal disruption; IS, irregular surface; WV, white villi & & & $>4$ \\
\hline
\end{tabular}

- Table 19 Small bowel cleanliness scales: Computer-dependent scales, quantitative scores.

\begin{tabular}{|c|c|c|c|c|}
\hline Reference & Capsule system & Preparation & Assessment parameters & Proportion of video analyzed \\
\hline $\begin{array}{l}\text { Van Weyen- } \\
\text { berg et al }\end{array}$ & PillCam & $2 \mathrm{LPEG}$ & $\begin{array}{l}\text { Mean intensity values of the green and red } \\
\text { channels of the SB segment of the tissue } \\
\text { colour bar }\end{array}$ & Tissue color bar - Entire video \\
\hline Ponte et al & Microcam & $\begin{array}{l}\text { Clear liquid diet, over- } \\
\text { night fast }\end{array}$ & $\begin{array}{l}\text { Mean intensity values of the green and red } \\
\text { channels of the SB segment of the tissue } \\
\text { colour bar }\end{array}$ & Map view bar - Entire video \\
\hline Klein et al & PillCam & $\begin{array}{l}\text { Clear liquid diet, over- } \\
\text { night fast }\end{array}$ & $\begin{array}{l}\text { Pixels of the SB segment of the tissue colour } \\
\text { bar }\end{array}$ & Tissue color bar - entire video \\
\hline Ali et al & PillCam & $\begin{array}{l}\text { Clear liquid diet, split } \\
\text { 1.5 L PEG, with or with- } \\
\text { out metoclopramide }\end{array}$ & Red/green pixel ratio of still frame images & $\begin{array}{l}\text { Tissue color bar of still frame } \\
\text { images }\end{array}$ \\
\hline Oumrani et al & PillCam & Not specified & $\begin{array}{l}\text { Colorimetry (red/green ratio), abundance } \\
\text { of bubbles, brightness }\end{array}$ & Still frame images \\
\hline
\end{tabular}

proach was then also used by Ali et al. Based on the $R / G$ pixel ratio of still frame images, they assessed the quality of SB cleansing. A SB-CAC score cut-off of 1.6 demonstrated a sensitivity of $91.3 \%$ and a specificity of $94.7 \%$, defining an adequate SB visualization [112].

This concept was also adapted to the OMOM and MiroCam CE systems. The MiroCam reading software, has a function named "Map View" and this is bar contains a representation of all the available recorded images recorded ( $\vee$ Fig. $15 a, ~ \triangleright$ Fig. 15b). Using the same methodology as that for PillCam, through photo editing software, the mean intensities of the red and green channels were determined. The authors used two different types of photo editing software and had identical results, resulting in an intra-test reliability of $1.0(P<0.001)$ [113].

Similar to the above computed scores, Klein et al designed and validated a computer algorithm based on the pixels in the tissue color bar of the CE PillCam system. Each pixel of the bar was independently labeled as adequate or inadequate. These were defined based on the pixel color and hue derived from the pixel RGB values. The computer algorithm then calculated and summarized the total number of "inadequate" pixels, their locations, the "adequate" to "inadequate" pixel ratio and the longest duration of consecutive "inadequate" pixels in the color bar. The computed classification of bowel preparation when compared to the subjective opinion of the authors had a sensitivity of $95 \%$, specificity $82 \%$ and a $90 \%$ accuracy [114]. A score allowing evaluation of the abundance of bubbles in CE still frames, based on Gray-level of co-occurrence matrix detector strategy, was developed. Based on this a score making use of still frames was developed and categorized as presenting with $<10 \%$ or $10 \%$ of bubbles and suggest that a $10 \%$ cut-off as being adequate with a sensitivity and specificity of $95 \%$ ( $>$ Fig. 16) [115].

More recently, Oumrani et al proposed a score based on three electronic parameters - colorimetry, abundance of bubbles, and brightness are assessed. These parameters were compared to the Brotz score as assessed by different experts, with a score of 7/10 being adequate mucosal visualization. Through automated analysis, the combination of the $R / G$ ratio, abundance of bubbles, and brightness achieved a sensitivity of $90.0 \%$ and a specificity of $87.7 \%$, with optimal reproducibility. Limitations of this score analysis are that it has been performed on still frames and not video analysis and on normal videos of patients with OGIB [116]. Though numerous automated scores have been proposed, to date no practical readily available score is available on the $C E$ reading software.

\section{Operator-dependent scores}

There are numerous studies that have evaluated the cleanliness of the SB through operator-dependent scores (> Table20, - Table 21, - Table 22). Most of the studies have used different bowel preparation regimens and all except one have used a similar type of capsule. The scores apply different descriptive methods - quantitative and/or qualitative. While quantitative measures apply a numerical score e. g. 1-10, qualitative scores make use of descriptive terms such as adequate and inadequate 

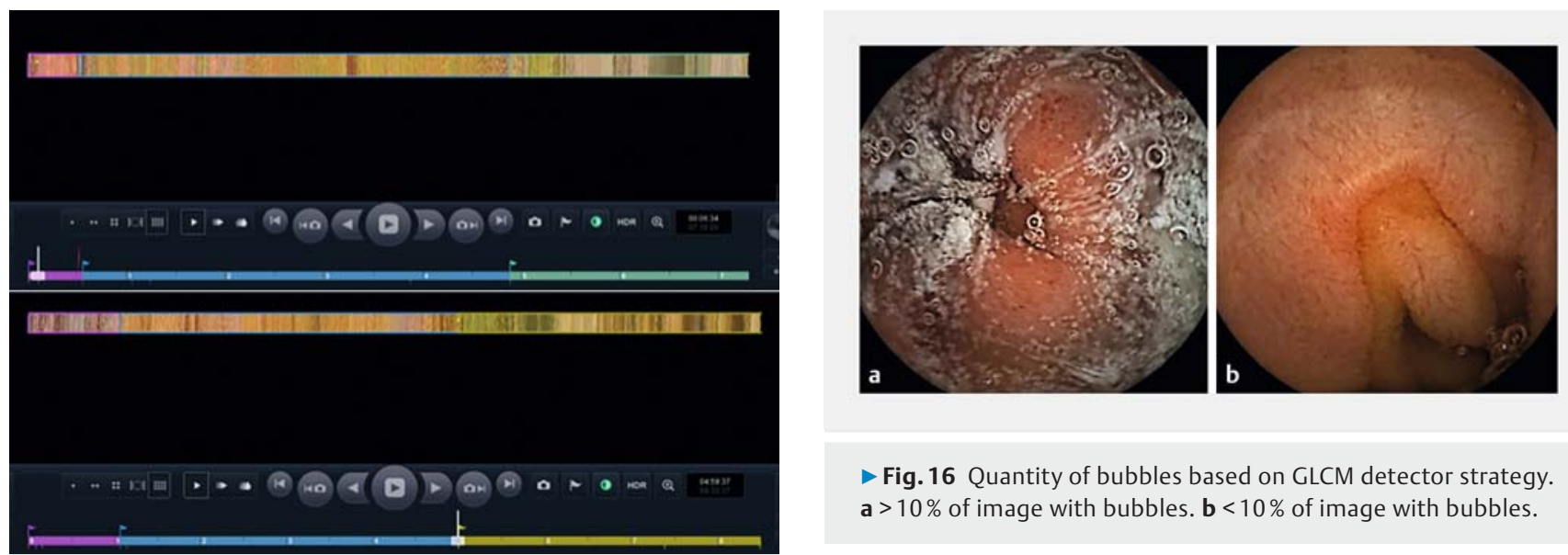

- Fig. 16 Quantity of bubbles based on GLCM detector strategy. a $>10 \%$ of image with bubbles. $\mathbf{b}<10 \%$ of image with bubbles.

- Fig. 15 MiroView's MapView bar consists of all images from the procedure compressed together, therefore, shows the color of each gastrointestinal tract.

- Table 20 Small bowel cleanliness scales: Human operator-dependent scales, quantitative scores.

\begin{tabular}{|c|c|c|c|c|}
\hline Reference & $\begin{array}{l}\text { Capsule } \\
\text { system }\end{array}$ & Preparation & Assessment parameters & $\begin{array}{l}\text { Proportion of video } \\
\text { analyzed }\end{array}$ \\
\hline Park et al & PillCam & 4L PEG & $\begin{array}{l}\text { Proportion of visualized mucosa and degree } \\
\text { of obscuration by bubbles, debris, and bile }\end{array}$ & $\begin{array}{l}\text { Consecutive single } \\
\text { frames }\end{array}$ \\
\hline QI - Brotz et al & PillCam & Clear Liquid diet, overnight fast & $\begin{array}{l}\text { QI based on percentage of mucosa visualized, } \\
\text { fluid and debris, bubbles, bile/chyme stain- } \\
\text { ing, and brightness }\end{array}$ & Entire video \\
\hline Spada et al & PillCam & $\begin{array}{l}\text { Clear liquid diet, overnight fast } \\
\text { or } 2 \text { L PEG and simethicone }\end{array}$ & Proportion of mucosa visualized & Entire video \\
\hline Oliva et al & PillCam & $\begin{array}{l}\text { Clear liquid diet and overnight } \\
\text { fast, or } 25 \text { or } 50 \mathrm{~mL} / \mathrm{kg} \text { of PEG, } \\
\text { and/or } 20 \mathrm{~mL} \text { of simethicone }\end{array}$ & Proportion of mucosa visualized & $\begin{array}{l}\text { Consecutive single } \\
\text { frames }\end{array}$ \\
\hline Van Tuyl et al & PillCam & $\begin{array}{l}\text { Clear liquid diet and overnight } \\
\text { fast, or } 1 \mathrm{~L} \text { of PEG, or } 2 \mathrm{~L} \text { of PEG }\end{array}$ & Proportion of mucosa visualized & Segments of video \\
\hline Caddy et al & - & $\begin{array}{l}250 \mathrm{~mL} \text { sodium picosulphate } \\
\text { plus } 500 \mathrm{~mL} \text { PEG with or with- } \\
\text { out erythromycin }\end{array}$ & Proportion of mucosa visualized & Entire video \\
\hline Viazis et al & PillCam & $\begin{array}{l}\text { Clear Liquid diet and overnight } \\
\text { fast, or } 2 \text { L PEG }\end{array}$ & $\begin{array}{l}\text { Proportion of unclean mucosa due to intes- } \\
\text { tinal debris }\end{array}$ & Entire video \\
\hline Kantianis et al & PillCam & 2 and $4 L$ of PEG & Proportion of mucosa visualized & $\begin{array}{l}\text { Consecutive single } \\
\text { frames }\end{array}$ \\
\hline Chen et al & OMOM & $\begin{array}{l}\text { Clear liquid diet and overnight } \\
\text { fast, or } 250 \mathrm{~mL} \text { mannitol with or } \\
\text { without simethicone }\end{array}$ & Proportion of mucosa visualized & $\begin{array}{l}\text { Consecutive single } \\
\text { frames }\end{array}$ \\
\hline Rosa et al & PillCam & $\begin{array}{l}\text { Clear liquid diet and overnight } \\
\text { fast, or } 2 \text { L PEG with or without } \\
\text { simethicone }\end{array}$ & Proportion of mucosa visualized & Entire video \\
\hline Nivet al & PillCam & $\begin{array}{l}\text { Clear liquid diet and overnight } \\
\text { fast or } \mathrm{NaP}\end{array}$ & Proportion of SBTT with invisible mucosa & Entire video \\
\hline Alageeli et al & PillCam & $\begin{array}{l}\text { Clear liquid diet, overnight fast, } \\
2 \text { L PEG }\end{array}$ & $\begin{array}{l}\text { Proportion of visualized mucosa and degree } \\
\text { of obscuration by bubbles, debris, and bile }\end{array}$ & $\begin{array}{l}\text { Consecutive single } \\
\text { frames }\end{array}$ \\
\hline
\end{tabular}


- Table 21 Small bowel cleanliness scales: Human operator-dependent scales, qualitative scores.

\begin{tabular}{|c|c|c|c|c|}
\hline Reference & $\begin{array}{l}\text { Capsule } \\
\text { system }\end{array}$ & Preparation & Assessment parameters & $\begin{array}{l}\text { Proportion of video } \\
\text { analyzed }\end{array}$ \\
\hline OAA - Brotz et al & PillCam & Clear liquid diet, overnight fast & Overall assessment of small-bowel cleansing & Entire video \\
\hline QE - Brotz et al & PillCam & Clear liquid diet, overnight fast & $\begin{array}{l}\text { QE based on percentage of mucosa visualized, } \\
\text { fluid and debris, bubbles, bile/chyme staining, } \\
\text { and brightness }\end{array}$ & Entire video \\
\hline Albert et al & PillCam & Overnight fast or simethicone & Mucosal invisibility due to intraluminal bubbles & Segments of video \\
\hline Pons Beltrán et al & PillCam & $\begin{array}{l}\text { Clear liquid diet, or } 90 \mathrm{~mL} \mathrm{NaP} \text {, or } \\
4 \mathrm{~L} \text { of PEG }\end{array}$ & Amounts of enteric residues & Entire video \\
\hline Nimomiya et al & PillCam & $\begin{array}{l}\text { Clear liquid diet and overnight } \\
\text { fast, or citrate magnesium }\end{array}$ & $\begin{array}{l}\text { Bubbles, food residues and intestinal juice col- } \\
\text { our }\end{array}$ & $\begin{array}{l}\text { Consecutive single } \\
\text { frames }\end{array}$ \\
\hline
\end{tabular}

- Table 22 Small bowel cleanliness scales: Human operator-dependent scales, quantitative and qualitative scores.

\begin{tabular}{|c|c|c|c|c|}
\hline Reference & $\begin{array}{l}\text { Capsule } \\
\text { system }\end{array}$ & Preparation & Assessment parameters & $\begin{array}{l}\text { Proportion of video } \\
\text { analyzed }\end{array}$ \\
\hline Esaki et al & PillCam & Simethicone or magnesium citrate & $\begin{array}{l}\text { Fluid transparency and proportion of nonvi- } \\
\text { sualized mucosa }\end{array}$ & Entire video \\
\hline Dai et al & PillCam & $4 \mathrm{~L}$ PEG or overnight fast & $\begin{array}{l}\text { Proportion of visualized mucosa and overall } \\
\text { visibility }\end{array}$ & Segments of video \\
\hline Lapalus et al & PillCam & $\begin{array}{l}\text { Clear liquid diet and overnight fast or } \\
\mathrm{NaP}\end{array}$ & $\begin{array}{l}\text { Proportion of visualized mucosa and amounts } \\
\text { of enteric liquid and bubbles }\end{array}$ & Segments of video \\
\hline Hooks et al & PillCam & $\begin{array}{l}\text { Clear liquid diet and overnight fast } \\
\text { with or without lubiprostone }\end{array}$ & $\begin{array}{l}\text { Proportion of mucosa visualized and amounts } \\
\text { of enteric debris }\end{array}$ & $\begin{array}{l}\text { Entire video and seg- } \\
\text { ments of video }\end{array}$ \\
\hline
\end{tabular}

- Table 23 Brotz Score.

\begin{tabular}{|c|c|c|c|c|c|}
\hline Points ${ }^{1}$ & $\begin{array}{l}\text { Percentage of mucosa } \\
\text { visualized }\end{array}$ & $\begin{array}{l}\text { Fluid and debris } \\
\text { abundance }\end{array}$ & Bubble abundance & Bile/chyme staining & Brightness reduction \\
\hline 0 & $<80 \%$ & Severe & Severe & Severe & Severe \\
\hline 1 & $80-89 \%$ & Moderate & Moderate & Moderate & Moderate \\
\hline 2 & $\geq 90 \%$ & Minimal/mild & Minimal/mild & Minimal/mild & Minimal/mild \\
\hline \multicolumn{6}{|l|}{ QE } \\
\hline Excellent & $\geq 90 \%$ & Absent/minimal & Absent/minimal & Absent/minimal & Absent/minimal \\
\hline Good & $\geq 90 \%$ & Mild & Mild & Mild & Mild \\
\hline Fair & $<90 \%$ & Moderate & Moderate & Moderate & Moderate \\
\hline Poor & $<80 \%$ & Excessive & Excessive & Excessive & Severe \\
\hline \multicolumn{6}{|l|}{ OAA } \\
\hline \multicolumn{6}{|l|}{ Adequate } \\
\hline Inadequat & & & & & \\
\hline
\end{tabular}




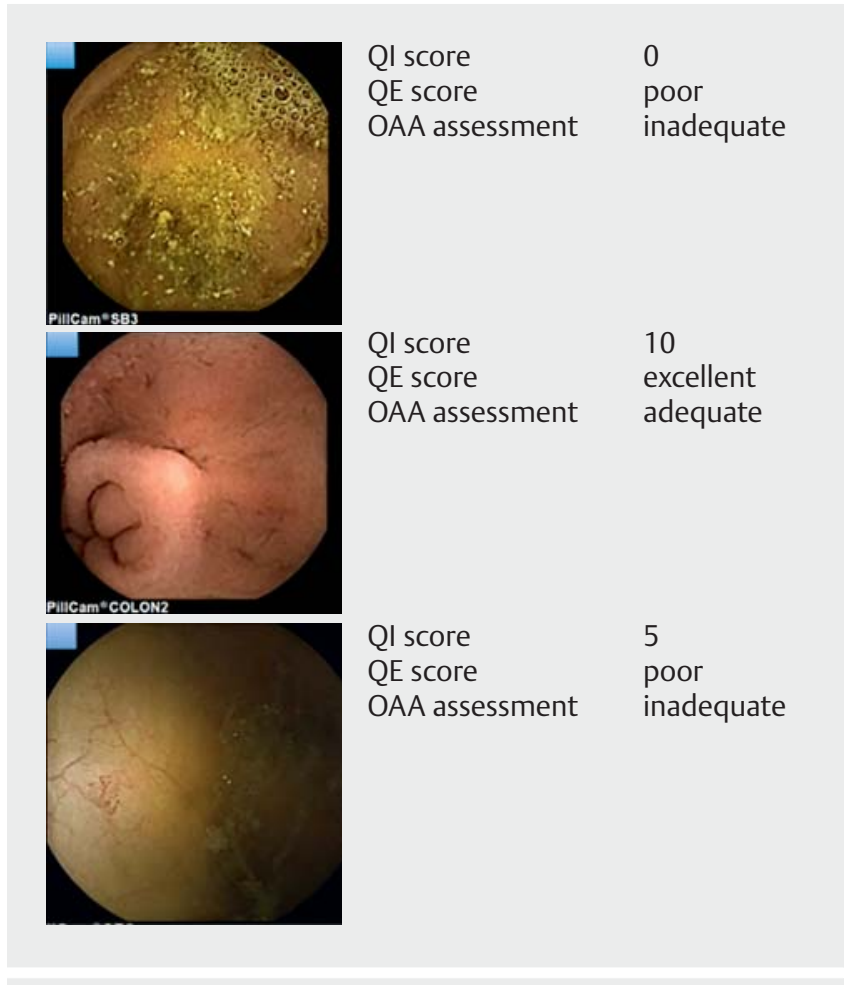

- Fig. 17 Brotz score applied to images from CE.

\begin{tabular}{|l|l|l|l|l|}
\hline Table 24 Park score. & & & \\
\hline Score & $\mathbf{0}$ & $\mathbf{1}$ & $\mathbf{2}$ & $\mathbf{3}$ \\
\hline $\begin{array}{l}\text { Percentage of mu- } \\
\text { cosa visualized }\end{array}$ & $\leq 25 \%$ & $25 \%-50 \%$ & $50 \%-75 \%$ & $\geq 75 \%$ \\
\hline Obscuration & $\geq 50 \%$ & $25 \%-50 \%$ & $5 \%-25 \%$ & $<5 \%$ \\
\hline
\end{tabular}

or poor, fair, good, excellent. Disadvantages for these scores are that they are operator-dependent and all time-consuming. In the absence of a universally accepted score, the two most commonly used scores, which are also mentioned in the ESGE document, on performance measures for SB endoscopy are the validated scores by Park et al. and Brotz et al $[117,118]$.

The validation study by Brotz et al was a prospective, randomized single-center study. In this study, $40 \mathrm{CE}$ videos (PillCam) were randomized and viewed by five CE readers, who proceeded to score the SB cleanliness based on the three scoring systems previously devised by Brotz et al ( $\$ Table 23). A month after the initial scoring, the same $40 \mathrm{CEs}$ were randomly reassigned to the same five readers who reevaluated the SB cleanliness based on the three scores. A clear liquid diet with overnight fast was employed prior to the CE. The three evaluated scales were; a quantitative index (QI $0-10$; higher scores corresponding to better cleansing), qualitative evaluation (poor, fair, good, excellent), and overall adequacy assessment (inadequate, adequate). In the evaluation, the QI score used all available frames ( $\triangleright$ Fig. 17) [22, 117-119].

Park et al developed a cleansing quantitative score based on the proportion of visualized mucosa and the degree of obscura-

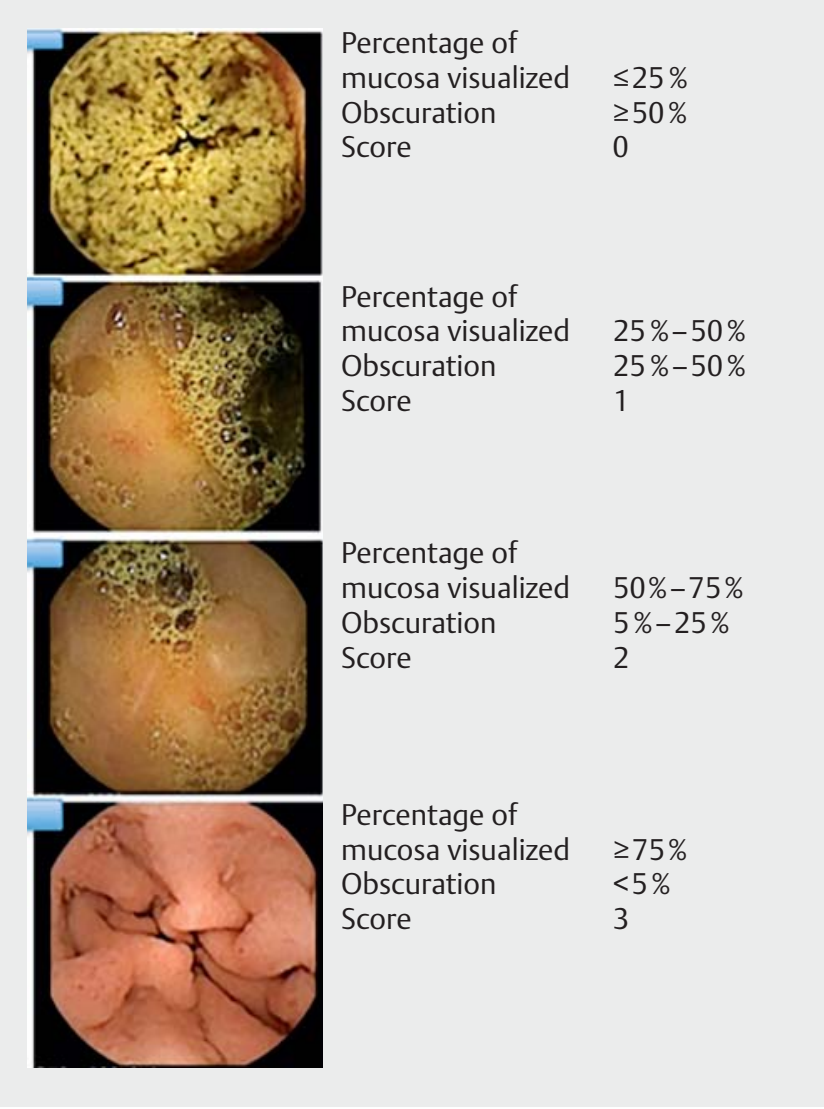

Fig. 18 Park Score applied to images from CE.

tion ( $\triangleright$ Table 24$)$. In contrast to the former score, the patients were given 4L PEG as bowel preparation. These two visual parameters were scored based on two four-step scales - (a) the proportion of visualized mucosa $(0-3)$ and (b) the degree of obscuration by bubbles, debris, and bile (0-3). These two parameters were evaluated in images from the entire SB selected at 5 -minute intervals. The overall score is obtained by summing the scores of all selected images and dividing them by the number of frames examined for each parameter. The final score is the average of the two mean scores. A cut-off value of 2.25 was proposed as adequate SB cleanliness by the authors. The main limitation of this score is that only one frame every $5 \mathrm{~min}$ utes is made use of, thus leaving the majority of frames unanalyzed ( $\triangleright$ Fig. 18) [117].

Today, a validated scale universally accepted for grading SB cleansing is still lacking. In fact, there are numerous grading systems with very different technical characteristics, namely, the parameters and the portion of the CE video that are analyzed, the objectivity of the analysis, the lesser or greater dependency on the operator, and the validation of the score. However, although time-consuming, the operator-dependent scores - Brotz and Park scores should be used during CE interpretation and these are also supported by ESGE ( $\sim$ Table 23 , - Table 24) [22]. The application of these scores will enable the clinician in assessing the reliability of the test, similarly to what is done during colonoscopy [120]. Further research is re- 
quired to be able to devise a reliable, reproducible, feasible and preferably automated score.

\section{Conclusions}

CE has become the mainstay of non-invasive diagnostic investigation for many diseases affecting the SB. Structured and standardized reporting is critical to improve the description of endoscopic findings and the consistency of image interpretation. The use of standardized scores is helpful in shortening the CE report, minimizing arbitrary or ambiguous descriptions, and summarizing the main findings and conclusions in a clear and clinically relevant manner. With this comprehensive review, we expect to facilitate and guide through using the currently available classification systems for small-bowel CE, as we believe this encloses a valuable potential to improve CE reading, increase the quality of the final report, and ultimately the strength of the recommendations for optimal patients management.

\section{Competing interests}

The authors declare that they have no conflict of interest.

\section{References}

[1] Iddan G, Meron G, Glukhovsky A et al. Wireless capsule endoscopy. Nature 2000; 405: 417

[2] MacLeod C, Wilson P, Watson AJM. Colon capsule endoscopy: an innovative method for detecting colorectal pathology during the COVID-19 pandemic? Colorectal Dis 2020; 22: 621-624

[3] Koulaouzidis A, Marlicz W, Wenzek $\mathrm{H}$ et al. Returning to digestive endoscopy normality will be slow and must include novelty and telemedicine. Dig Liver Dis 2020; 52: 1099-1101

[4] Vasilakakis MD, Koulaouzidis A, Marlicz W et al. The future of capsule endoscopy in clinical practice: from diagnostic to therapeutic experimental prototype capsules. Prz Gastroenterol 2020; 15: 179193

[5] Steiger C, Abramson A, Nadeau P et al. Ingestible electronics for diagnostics and therapy. Nat Rev Mater 2019; 5: 83-98

[6] Ding Z, Shi H, Zhang $\mathrm{H}$ et al. Gastroenterologist-level identification of small-bowel diseases and normal variants by capsule endoscopy using a deep-learning model. Gastroenterology 2019; 157: 10441054 e1045

[7] Min JK, Kwak MS, Cha JM. Overview of deep learning in gastrointestinal endoscopy. Gut Liver 2019; 13: 388-393

[8] Fernandez-Urien I, Panter S, Carretero C et al. International core curriculum for capsule endoscopy training courses. Endosc Int Open 2017; 5: E526-E538

[9] Sidhu R, Chetcuti Zammit S, Baltes P et al. Curriculum for smallbowel capsule endoscopy and device-assisted enteroscopy training in Europe: European Society of Gastrointestinal Endoscopy (ESGE) Position Statement. Endoscopy 2020; 52: 669-686

[10] Pioche M, Filoche B, Jacob P et al. Randomized Prospective Comparison of the Diagnostic yield of PillCam SB2 and Mirocam videocapsules in patients with obscure digestive bleeding. Gastrointest Endosc 2011; 73: 1181-1188
11] Saurin JC, Ben Soussan E, Gaudric M et al. Can we shorten the smallbowel capsule reading time? validation of the "quick-view" image detection system Gastrointest Endosc 2009; 69: AB189 (abstr.)

[12] Leenhardt R, Li C, Koulaouzidis A et al. Nomenclature and semantic description of vascular lesions in small bowel capsule endoscopy: an international Delphi consensus statement. Endosc Int Open 2019; 7: E372-E379

[13] Leenhardt R, Buisson A, Bourreille A et al. Nomenclature and semantic descriptions of ulcerative and inflammatory lesions seen in Crohn's disease in small bowel capsule endoscopy: An international Delphi consensus statement. United European Gastroenterol J 2020; 8: 99-107

[14] Gerson LB, Fidler JL, Cave DR et al. ACG Clinical Guideline: Diagnosis and Management of Small Bowel Bleeding. Am J Gastroenterol 2015; 110: $1265-87$ quiz 1288

[15] Pennazio M, Spada C, Eliakim R et al. Small-bowel capsule endoscopy and device-assisted enteroscopy for diagnosis and treatment of small-bowel disorders: European Society of Gastrointestinal Endoscopy (ESGE) Clinical Guideline. Endoscopy 2015; 47: 352-376

[16] Liao Z, Gao R, Xu C et al. Indications and detection, completion, and retention rates of small-bowel capsule endoscopy: a systematic review. Gastrointest Endosc 2010; 71: 280-286

[17] Islam RS, Leighton JA, Pasha SF. Evaluation and management of small-bowel tumors in the era of deep enteroscopy. Gastrointest Endosc 2014; 79: 732-740

[18] Song JH, Hong SN, Kyung ChangD et al. The etiology of potentia small-bowel bleeding depending on patient's age and gender. United European Gastroenterol J 2018; 6: 1169-1178

[19] Saurin JC, Delvaux M, Gaudin JL et al. Diagnostic value of endoscopic capsule in patients with obscure digestive bleeding: blinded comparison with video push-enteroscopy. Endoscopy 2003; 35: 576-584

[20] Saurin JC, Delvaux M, Vahedi K et al. Clinical impact of capsule endoscopy compared to push enteroscopy: 1-year follow-up study. Endoscopy 2005; 37: 318-323

[21] Rahmi G, Samaha E, Vahedi K et al. Long-term follow-up of patients undergoing capsule and double-balloon enteroscopy for identification and treatment of small-bowel vascular lesions: a prospective, multicenter study. Endoscopy 2014; 46: 591-597

[22] Spada C, McNamara D, Despott E] et al. Performance measures for small-bowel endoscopy: A European Society of Gastrointestinal Endoscopy (ESGE) Quality Improvement Initiative. United Europ Gastroenterol ] 2019; 7: 614-641

[23] Saurin JC, Pilleul F, Soussan EB et al. Small-bowel capsule endoscopy diagnoses early and advanced neoplasms in asymptomatic patients with Lynch syndrome. Endoscopy 2010; 42: 1057-1062

[24] Rondonotti E, Pennazio M, Toth E et al. How to read small bowel capsule endoscopy: a practical guide for everyday use. Endosc Int Open 2020; 8: E1-E5

[25] Yano T, Yamamoto H, Sunada K et al. Endoscopic classification of vascular lesions of the small intestine (with videos). Gastrointest Endosc 2008; 67: 169-172

[26] Arieira C, Magalhães R, Dias de Castro F et al. Small bowel angioectasias rebleeding and the identification of higher risk patients [published online ahead of print, 2020 Feb 18]. Dig Dis Sci 2021; 66: 175-180

[27] Shinozaki S, Yamamoto H, Yano T et al. Favorable long-term outcomes of repeat endotherapy for small-intestine vascular lesions by double-balloon endoscopy. Gastrointest Endosc 2014; 80: 112-117

[28] Lepileur L, Dray X, Antonietti M et al. Factors associated with diagnosis of obscure gastrointestinal bleeding by video capsule enteroscopy. Clin Gastroenterol Hepatol 2012; 10: 1376-1380

[29] Pennazio M, Santucci R, Rondonotti E et al. Outcome of patients with obscure gastrointestinal bleeding after capsule endoscopy: re- 
port of 100 consecutive cases. Gastroenterology 2004; 126: 643653

[30] Nennstiel S, Machanek A, von Delius S et al. Predictors and characteristics of angioectasias in patients with obscure gastrointestinal bleeding identified by video capsule endoscopy. United Europ Gastroenterol ] 2017; 5: 1129-1135

[31] Shahidi NC, Ou G, Svarta S et al. Factors associated with positive findings from capsule endoscopy in patients with obscure gastrointestinal bleeding. Clin Gastroenterol Hepatol 2012; 10: 1381-1385

[32] Pate GE, Mulligan A. An epidemiological study of Heyde's syndrome: an association between aortic stenosis and gastrointestinal bleeding. J Heart Valve Dis 2004; 13: 713-716

[33] Tabibian JH, Rhoades DP, Forde KA et al. Timing of gastrointestinal bleeding after implantation of left ventricular assist devices associates with anatomic location, presentation, and management. Clin Gastroenterol Hepatol 2019; 17: 448-454

[34] Igawa A, Oka S, Tanaka S et al. Major predictors and management of small-bowel angioectasia. BMC Gastroenterol 2015; 15: 108

[35] Holleran G, Hall B, Hussey M et al. Small bowel angiodysplasia and novel disease associations: a cohort study. Scand J Gastroenterol 2013; 48: 433-438

[36] Veyradier A, Balian A, Wolf M et al. Abnormal von Willebrand factor in bleeding angiodysplasias of the digestive tract. Gastroenterology 2001; 120: 346-353

[37] Sidhu R, Sanders DS, Kapur K et al. Factors predicting the diagnostic yield and intervention in obscure gastrointestinal bleeding investigated using capsule endoscopy. J Gastrointestin Liver Dis 2009; 18: 273-278

[38] Garcia-Compean D, Del Cueto-Aguilera AN, Jimenez-Rodriguez AR et al. Diagnostic and therapeutic challenges of gastrointestinal angiodysplasias: A critical review and view points. World J Gastroenterol 2019; 25: 2549-2564

[39] Tziatzios G, Gkolfakis P, Papanikolaou IS et al. antithrombotic treatment is associated with small-bowel video capsule endoscopy positive findings in obscure gastrointestinal bleeding: a systematic review and meta-analysis. Dig Dis Sci 2019; 64: 15-24

[40] Boal Carvalho P, Rosa B, Moreira MJ et al. New evidence on the impact of antithrombotics in patients submitted to small bowel capsule endoscopy for the evaluation of obscure gastrointestinal bleeding. Gastroenterol Res Pract 2014; 2014: 709217

[41] Marya N, Wang L, Dasharathy S et al. Development of a scoring system to predict a positive diagnosis on video capsule endoscopy for suspected small bowel bleeding. Tech Innov Gastrointest Endosc 2020; 22: 178-184

[42] Ohmiya N, Nakamura M, Osaki H et al. Development of a comorbidity index to identify patients with small bowel bleeding at risk for rebleeding and small bowel vascular diseases. Clin Gastroenterol Hepatol 2019; 17: 896-904 e4

[43] Wetwittayakhlang P, Wonglhow ], Netinatsunton N et al. Re-bleeding and its predictors after capsule endoscopy in patients with obscure gastrointestinal bleeding in long-term follow-up. BMC Gastroenterol 2019; 19: 216

[44] Ponte A, Perez-Cuadrado Robles E, Pinho R et al. High short-term rebleeding rate in patients undergoing a second endoscopic therapy for small-bowel angioectasias after recurrent bleeding. Rev Esp Enferm Dig 2018; 110: 88-93

[45] Matsumura T, Arai M, Saito K et al. Predictive factor of re-bleeding after negative capsule endoscopy for obscure gastrointestinal bleeding: over 1-year follow-up study. Dig Endosc 2014; 26: 650658

[46] Fan GW, Chen TH, Lin WP et al. Angiodysplasia and bleeding in the small intestine treated by balloon-assisted enteroscopy. J Dig Dis 2013; 14: 113-116
[47] Tan W, Ge ZZ, Gao Y] et al. Long-term outcome in patients with obscure gastrointestinal bleeding after capsule endoscopy. J Dig Dis 2015; 16: 125-134

[48] Koh SJ, Im JP, Kim JW et al. Long-term outcome in patients with obscure gastrointestinal bleeding after negative capsule endoscopy. World J Gastroenterol 2013; 19: 1632-1638

[49] Sakai E, Endo H, Taguri M et al. Frequency and risk factors for rebleeding events in patients with small bowel angioectasia. BMC Gastroenterol 2014; 14: 200

[50] Romagnuolo J, Brock AS, Ranney N. Is endoscopic therapy effective for angioectasia in obscure gastrointestinal bleeding? A systematic review of the literature J Clin Gastroenterol 2015; 49: 823-830

[51] Jackson CS, Gerson LB. Management of gastrointestinal angiodysplastic lesions (gastrointestinalADs): a systematic review and metaanalysis. Am J Gastroenterol 2014; 109: 474-83 quiz 484

[52] Gerson LB, Batenic MA, Newsom SL et al. Long-term outcomes after double-balloon enteroscopy for obscure gastrointestinal bleeding. Clin Gastroenterol Hepatol 2009; 7: 664-669

[53] Ribeiro I, Pinho R, Rodrigues A et al. What is the long-term outcome of a negative capsule endoscopy in patients with obscure gastrointestinal bleeding? Rev Esp Enferm Dig 2015; 107: 753-758

[54] May A, Friesing-Sosnik T, Manner $\mathrm{H}$ et al. Long-term outcome after argon plasma coagulation of small-bowel lesions using double-balloon enteroscopy in patients with mid-gastrointestinal bleeding. Endoscopy 2011; 43: 759-765

[55] Esaki M, Matsumoto T, Yada S et al. Factors associated with the clinical impact of capsule endoscopy in patients with overt obscure gastrointestinal bleeding. Dig Dis Sci 2010; 55: 2294-2301

[56] Neu B, Ell C, May A et al. Capsule endoscopy versus standard tests in influencing management of obscure digestive bleeding: results from a German multicenter trial. Am J Gastroenterol 2005; 100: $1736-1742$

[57] Canas-Ventura A, Marquez L, Bessa X et al. Outcome in obscure gastrointestinal bleeding after capsule endoscopy. World J Gastrointest Endosc 2013; 5: 551-558

[58] Yung DE, Koulaouzidis A, Avni T et al. Clinical outcomes of negative small-bowel capsule endoscopy for small-bowel bleeding: a systematic review and meta-analysis. Gastrointest Endosc 2017; 85: 305-317 e2

[59] Lai LH, Wong GL, Chow DK et al. Long-term follow-up of patients with obscure gastrointestinal bleeding after negative capsule endoscopy. Am J Gastroenterol 2006; 101: 1224-1228

[60] Samaha E, Rahmi G, Landi B et al. Long-term outcome of patients treated with double balloon enteroscopy for small bowel vascular lesions. Am J Gastroenterol 2012; 107: 240-246

[61] Grooteman KV, Holleran G, Matheeuwsen M et al. A risk assessment of factors for the presence of angiodysplasias during endoscopy and factors contributing to symptomatic bleeding and rebleeds. Dig Dis Sci 2019; 64: 2923-2932

[62] Redondo-Cerezo E, Gomez-Ruiz C], Sanchez-Manjavacas N et al. Long-term follow-up of patients with small-bowel angiodysplasia on capsule endoscopy. Determinants of a higher clinical impact and rebleeding rate. Rev Esp Enferm Dig 2008; 100: 202-207

[63] Davie M, Yung DE, Douglas S et al. Mapping the distribution of small bowel angioectasias. Scand J Gastroenterol 2019; 54: 597-602

[64] Jackson CS, Strong R. Gastrointestinal Angiodysplasia: Diagnosis and Management. Gastrointest Endosc Clin N Am 2017; 27: 51-62

[65] Baba Y, Kawano S, Kono Y et al. Clinical characteristics and risk factors for rebleeding in patients with obscure gastrointestinal bleeding. Intern Med 2020; 59: 1345-1350

[66] Karagiannis S, Goulas S, Kosmadakis G et al. Wireless capsule endoscopy in the investigation of patients with chronic renal failure 
and obscure gastrointestinal bleeding (preliminary data). World Gastroenterol 2006; 12: 5182-5185

[67] de Sousa Magalhaes R, Curdia Goncalves T, Rosa B et al. RHEMITT score: predicting the risk of rebleeding for patients with mid-gastrointestinal bleeding submitted to small bowel capsule endoscopy. Dig Dis 2020; 38: 299-309

[68] Silva JC, Pinho R, Ponte $A$ et al. Predicting the risk of rebleeding after capsule endoscopy in obscure gastrointestinal bleeding - External validation of the RHEMITT Score. Dig Dis 2020: doi:10.1159/ 000509986

[69] Uchida G, Hirooka Y, Nakamura M et al. Nomogram-based prediction of rebleeding in small bowel bleeding patients: the 'PRSBB' score. Sci Rep 2018; 8: 6378

[70] Uchida G, Nakamura M, Watanabe O et al. Development and validation of a new scoring system to determine the necessity of smallbowel endoscopy in obscure gastrointestinal bleeding. Dig Liver Dis 2017; 49: 1218-1224

[71] Niikura R, Yamada A, Nagata $\mathrm{N}$ et al. New predictive model of rebleeding during follow-up of patents with obscure gastrointestinal bleeding: A multicenter cohort study. J Gastroenterol Hepatol 2016; 31: 752-760

[72] O'Brien EC, Simon DN, Thomas LE et al. The ORBIT bleeding score: a simple bedside score to assess bleeding risk in atrial fibrillation. Eur Heart J 2015; 36: 3258-3264

[73] Curdia GoncalvesT, Arieira C, Monteiro S et al. ORBIT score: an useful predictor of small bowel rebleeding in patients under chronic anticoagulation. Scand J Gastroenterol 2018; 53: 179-184

[74] Rondonotti E, Spada C, Adler S et al. Small-bowel capsule endoscopy and device-assisted enteroscopy for diagnosis and treatment of small-bowel disorders: European Society of Gastrointestinal Endoscopy (ESGE) Technical Review. Endoscopy 2018; 50: 423-446

[75] Pérez-Cuadrado Robles E, Pinho R, González-Suárez B et al. Small bowel enteroscopy - A joint clinical guideline by the Spanish and Portuguese small-bowel study groups. Rev Esp Enferm Dig 2020; 112: 309-318

[76] Gay G, Delvaux M, Fassler I. Outcome of capsule endoscopy in determining indication and route for push-and-pull enteroscopy. Endoscopy 2006; 38: 49-58

[77] Nakamura M, Ohmiya N, Shirai O et al. Route selection for doubleballoon endoscopy, based on capsule transit time, in obscure gastrointestinal bleeding. J Gastroenterol 2010; 45: 592-599

[78] Maeda Y, Moribata K, Deguchi H et al. Video capsule endoscopy as the initial examination for overt obscure gastrointestinal bleeding can efficiently identify patients who require double-balloon enteroscopy. BMC Gastroenterol 2015; 15: 132

[79] Li X, Chen H, Dai J et al. Predictive role of capsule endoscopy on the insertion route of double-balloon enteroscopy. Endoscopy 2009; 41 : 762-766

[80] Lin T-N, Su M-Y, Hsu C-M et al. Combined use of capsule endoscopy and double-balloon enteroscopy in patients with obscure gastrointestinal bleeding. Chang Gung Med J 2008; 31: 450-456

[81] Chalazan B, Gostout CJ, Song LM et al. Use of capsule small bowel transit time to determine the optimal enteroscopy approach. Gastroenterology Res 2012; 5: 39-44

[82] Tsuboi A, Oka S, Tanaka S et al. The Clinical usefulness of the pillcam progress indicator for route selection in double balloon endoscopy. Intern Med 2019; 58: 1375-1381

[83] Mandaliya R, Korenblit J, O’Hare B et al. Spiral enteroscopy utilizing capsule location index for achieving high diagnostic and therapeutic yield. Diagn Ther Endosc 2015; 2015: 1-7

[84] Jensen MD, Nathan T, Rafaelsen SR et al. Diagnostic accuracy of capsule endoscopy for small bowel Crohn's disease is superior to that of MR enterography or CT enterography. Clin Gastroenterol Hepatol 2011; 9: 124-129

[85] Bar-Meir S. Review article: capsule endoscopy - are all small intestinal lesions Crohn's disease? Aliment Pharmacol Ther 2006; 24 : 19-21

[86] Gralnek IM, Defranchis R, Seidman E et al. Development of a capsule endoscopy scoring index for small bowel mucosal inflammatory change. Aliment Pharmacol Ther 2008; 27: 146-154

[87] Cotter J, Dias de Castro F, Magalhaes J et al. Validation of the Lewis score for the evaluation of small-bowel Crohn's disease activity. Endoscopy 2015; 47: 330-335

[88] Rosa B, Moreira MJ, Rebelo A et al. Lewis Score: a useful clinical tool for patients with suspected Crohn's Disease submitted to capsule endoscopy. J Crohn's Colitis 2012; 6: 692-697

[89] Santos A, Silva MA, Cardoso H et al. Lewis score: a useful tool for diagnosis and prognosis in Crohn's disease. Rev Esp Enferm Dig 2020; 112: $121-126$

[90] Ben-Horin S, Lahat A, Amitai MM et al. Assessment of small bowel mucosal healing by video capsule endoscopy for the prediction of short-term and long-term risk of Crohn's disease flare: A prospective cohort study. Lancet Gastroenterol Hepatol 2019; 4: 519-528

[91] Gal E, Geller A, Fraser G et al. Assessment and Validation of the New Capsule Endoscopy Crohn's Disease Activity Index (CECDAI). Dig Dis Sci 2008; 53: 1933-1937

[92] Niv Y, Ilani S, Levi Z et al. Validation of the Capsule Endoscopy Crohn's Disease Activity Index (CECDAI or Niv score): a multicenter prospective study. Endoscopy 2012; 44: 21-26

[93] Koulaouzidis A, Douglas S, Plevris JN. Lewis score correlates more closely with fecal calprotectin than capsule endoscopy Crohn's disease activity index. Dig Dis Sci 2012; 57: 987-993

[94] Ponte A, Pinho R, Rodrigues A et al. Evaluation and comparison of capsule endoscopy scores for assessment of inflammatory activity of small-bowel in Crohn's disease. Gastroenterol Hepatol 2018; 41: 245-250

[95] Yablecovitch D, Lahat A, Neuman S et al. The Lewis score or the capsule endoscopy Crohn's disease activity index: which one is better for the assessment of small bowel inflammation in established Crohn's disease? Therap Adv Gastroenterol 2018; 11 : $1756283 \times 17747780$

[96] Kopylov U, Nemeth A, Koulaouzidis A et al. Small bowel capsule endoscopy in the management of established Crohn's disease: clinical impact, safety, and correlation with inflammatory biomarkers. Inflamm Bowel Dis 2015; 21: 93-100

[97] Buchman AL, Miller FH, Wallin A et al. Video capsule endoscopy versus barium contrast studies for the diagnosis of Crohn's disease recurrence involving the small intestine. Am J Gastroenterol 2004; 99: 2171-2177

[98] Graham DY, Opekun AR, Willingham FF et al. Visible small-intestina mucosal injury in chronic NSAID users. Clin Gastroenterol Hepatol 2005; 3: 55-59

[99] Niv Y, Gal E, Gabovitz V et al. Capsule endoscopy Crohn's disease activity index (CECDAlic or Niv Score) for the small bowel and colon. J Clin Gastroenterol 2018; 52: 45-49

[100] Arieira C, Magalhães R, Dias de Castro F et al. CECDAlic - a new useful tool in pan-intestinal evaluation of Crohn's disease patients in the era of mucosal healing. Scand J Gastroenterol 2019; 54: 1326-1330

[101] Eliakim R, Spada C, Lapidus A et al. Evaluation of a new pan-enteric video capsule endoscopy system in patients with suspected or established inflammatory bowel disease - feasibility study. Endosc Int Open 2018; 6: E1235-E1246

[102] Eliakim R, Yablecovitch D, Lahat A et al. A novel PillCam Crohn's capsule score (Eliakim score) for Quantification of mucosal inflam- 
mation in Crohn's disease. United European Gastroenterol ] 2020; 8: 544-551

[103] Zagorowicz ES, Pietrzak AM, Wronska E et al. Small bowel tumors detected and missed during capsule endoscopy: single center experience. World J Gastroenterol 2013; 19: 9043-9048

[104] Postgate A, Despott E, Burling D et al. Significant small-bowel lesions detected by alternative diagnostic modalities after negative capsule endoscopy. Gastrointest Endosc 2008; 68: 1209-1214

[105] Girelli CM, Porta P, Colombo E et al. Development of a novel index to discriminate bulge from mass on small-bowel capsule endoscopy. Gastrointest Endosc 2011; 74: 1067-1074

[106] Hatem G, Buda A, Caccaro A et al. Bulges on small-bowel capsule endoscopy: innocent lesions we should take with a pinch of SPICE. UEG; 2014

[107] Rodrigues JP, Pinho R, Rodrigues A et al. Validation of SPICE, a method to differentiate small-bowel submucosal lesions from innocent bulges on capsule endoscopy. Rev Esp Enferm Dig 2017; 109: 106-113

[108] Min M, Noujaim MG, Green J et al. Role of mucosal protrusion angle in discriminating between true and false masses of the small-bowel on video capsule endoscopy. J Clin Med 2019; 8: 418

[109] Shying LR, Lin SC, Shih SC et al. Proposed scoring system to determine small bowel mass lesions using capsule endoscopy. J Formos Med Assoc 2009; 108: 533-538

[110] Calderwood AH, Schroy PC, Lieberman DA et al. Boston Bowel Preparation Scale scores provide a standardized definition of adequate for describing bowel cleanliness. Gastrointest Endosc 2014; 80: 269-276

[111] Van Weyenberg SJ, De Leest HT, Mulder C]. Description of a novel grading system to assess the quality of bowel preparation in video capsule endoscopy. Endoscopy 2011; 43: 406-411
[112] Abou AliE, Histace A, Camus M et al. Development and validation of a computed assessment of cleansing score for evaluation of quality of small-bowel visualization in capsule endoscopy. Endosc Int Open 2018; 6: E646-E651

[113] Ponte A, Pinho R, Rodrigues A et al. Validation of the Computed Assessment of Cleansing score with the Mirocam ${ }^{\circledR}$ system. Rev Esp Enferm Dig 2016; 108: 709-715

[114] Klein A, Gizbar M, Bourke M et al. A validated computerized cleansing score for Video Capsule Endoscopy. Dig Endosc 2015; 28: 564569

[115] Pietri O, Rezgui G, Histace A et al. Development and validation of an automated algorithm to evaluate the abundance of bubbles in smal bowel capsule endoscopy. Endosc Int Open 2018; 6: E462-E469

[116] Oumrani S, Histace A, Abou Ali E et al. Multi-criterion, automated, high-performance, rapid tool for assessing mucosal visualization quality of still images in small bowel capsule endoscopy. Endosc Int Open 2019; 7: E944-E948

[117] Park SC, Keum B, Hyun JJ et al. A novel cleansing score system for capsule endoscopy. World J Gastroenterol 2010; 16: 875-880

[118] Brotz C, Nandi N, Conn M et al. A validation study of 3 grading systems to evaluate small-bowel cleansing for wireless capsule endoscopy: a quantitative index, a qualitative evaluation, and an overall adequacy assessment. Gastrointest Endosc 2009; 69: 262-270.e1

[119] Ponte A, Pinho R, Rodrigues A et al. Review of small-bowel cleansing scales in capsule endoscopy: A panoply of choices. World J Gastrointest Endosc 2016; 8: 600-609

[120] Lai E], Calderwood AH, Doros G et al. The Boston bowel preparation scale: a valid and reliable instrument for colonoscopy-oriented research. Gastrointest Endosc 2009; 69: 620-625 